\title{
Orexin, cardio-respiratory function, and hypertension
}

\section{Aihua $\mathrm{Li}^{*}$ and Eugene Nattie}

Department of Physiology and Neurobiology, Geisel School of Medicine at Dartmouth, Lebanon, NH, USA

\section{Edited by:}

Michel A. Steiner, Actelion

Pharmaceuticals Ltd., Switzerland

\section{Reviewed by:}

Renato Corradetti, University of

Florence, Italy

Vincenzo Donadio, IRCCS Istituo

delle Scienze Neurologiche di

Bologna, Italy

Ling-Ling Hwang, Taipei Medical

University, Taiwan

\section{*Correspondence:}

Aihua Li, Department of Physiology and Neurobiology, Geisel School of Medicine at Dartmouth 1 Medical Center Drive, Lebanon, NH 03756, USA

e-mail: aihua.li@dartmouth.edu
In this review we focus on the role of orexin in cardio-respiratory functions and its potential link to hypertension. (1) Orexin, cardiovascular function, and hypertension. In normal rats, central administration of orexin can induce significant increases in arterial blood pressure (ABP) and sympathetic nerve activity (SNA), which can be blocked by orexin receptor antagonists. In spontaneously hypertensive rats (SHRs), antagonizing orexin receptors can significantly lower blood pressure under anesthetized or conscious conditions. (2) Orexin, respiratory function, and central chemoreception. The prepro-orexin knockout mouse has a significantly attenuated ventilatory $\mathrm{CO}_{2}$ chemoreflex, and in normal rats, central application of orexin stimulates breathing while blocking orexin receptors decreases the ventilatory $\mathrm{CO}_{2}$ chemoreflex. Interestingly, SHRs have a significantly increased ventilatory $\mathrm{CO}_{2}$ chemoreflex relative to normotensive WKY rats and blocking both orexin receptors can normalize this exaggerated response. (3) Orexin, central chemoreception, and hypertension. SHRs have higher ABP and SNA along with an enhanced ventilatory $\mathrm{CO}_{2}$ chemoreflex. Treating SHRs by blocking both orexin receptors with oral administration of an antagonist, almorexant (Almxt), can normalize the $\mathrm{CO}_{2}$ chemoreflex and significantly lower ABP and SNA. We interpret these results to suggest that the orexin system participates in the pathogenesis and maintenance of high blood pressure in SHRs, and the central chemoreflex may be a causal link to the increased SNA and ABP in SHRs. Modulation of the orexin system could be a potential target in treating some forms of hypertension.

Keywords: orexin and orexin receptors, cardiorespiratory function, hypertension, $\mathrm{CO} 2$ chemoreflex, blood pressure regulation

\section{INTRODUCTION}

Orexins, also known as hypocretins (Hcrt), are two excitatory neuropeptides, orexin A and orexin B (OX-A and OX-B) or hypocretin 1 and hypocretin 2 (Hcrt1 and Hcrt 2), produced by neurons primarily located in the lateral hypothalamic area (LHA) (De Lecea et al., 1998; Sakurai et al., 1998). Both OX-A and OX-B are derived from the same neuropeptide precursor, prepro-orexin (pp-OX or Hcrt gene). The actions of OX-A and OX-B are mediated by two G-protein coupled receptors, orexin receptor-1 $\left(\mathrm{OX}_{1} \mathrm{R} / \mathrm{HcrtR} 1\right)$ and orexin receptor-2 $\left(\mathrm{OX}_{2} \mathrm{R} / \mathrm{HcrtR} 2\right)$. Mounting evidence suggests that orexin is not only important to sleep-wake cycle and feeding regulation but also to respiratory and cardiovascular regulation. Furthermore, orexin may play role in some types of hypertension.

\section{OREXIN AND OREXIN RECEPTORS}

The anatomical and physiological properties of the orexin system have been reviewed extensively by many recent publications (Sakurai, 2007; Tsujino and Sakurai, 2009; De Lecea, 2012). In this review we focus only on orexin functions of most relevance to cardio-respiratory regulation.

\section{OREXIN NEURONS}

In the central nervous system (CNS), the cell bodies of orexin neurons are strictly located in the perifornical area and lateral and dorsal hypothalamic areas (Peyron et al., 1998; Date et al., 1999; Nambu et al., 1999). Orexin neurons receive afferents from GABA, serotonin and catecholamine neurons, and interact in the LHA with neurons that produce melanin concentrating hormone $(\mathrm{MCH})$ and with neurons that express the leptin receptor (LepR) (Bayer et al., 2005; Leinninger and Myers, 2008; Schone et al., 2011, 2012; Burdakov et al., 2013; Karnani et al., 2013). Serotonin (5-HT) hyperpolarizes orexin neurons through 5- $\mathrm{HT}_{1} \mathrm{~A}$ receptor mediated G-protein-coupled inward rectifier potassium channels (GIRK) in hypothalamic slices prepared from orexin neuron/enhanced green fluorescent protein (EGFP) transgenic mice (Muraki et al., 2004). The majority of orexin-immunoreactive (OX-ir) neurons in LHA are surrounded by dense tyrosine hydroxylase-immunoreactive (TH-ir) axons (Yamanaka et al., 2006), but results of studies on the role of catecholamines in orexin neurons are inconsistent. Bayer et al. showed that noradrenaline depolarized and excited orexin neurons (Bayer et al., 2005), while Yamanaka et al. reported that catecholamines directly and indirectly inhibited orexin neurons via $\alpha 2$-adrenoceptor mediated activation of GIRK channels (Yamanaka et al., 2006).

In the LHA, three major types of neurons $\mathrm{OX}, \mathrm{MCH}$, and LepRb expressing neurons are tightly intermingled and have a complex interactive relationship. An emerging hypothesis is that OX-MCH-LepR micro-circuits may act to regulate both autonomic function and energy balance (Leinninger and Myers, 2008; Hall et al., 2010; Leinninger, 2011; Burdakov et al., 2013). OX 
neurons are most active during wakefulness (Hassani et al., 2009), and activation of orexin receptors promotes wakefulness (De Lecea, 2010, 2012; Sakurai et al., 2010), feeding, and energy metabolism (Tsujino and Sakurai, 2009; Teske et al., 2010; Girault et al., 2012; Nixon et al., 2012), excites breathing, and stimulates sympathetic nerve activity (SNA) leading to an increase in blood pressure (Matsumura et al., 2001; Shirasaka et al., 2002; Zhang et al., 2005; Huang et al., 2010; Shahid et al., 2011, 2012; Nattie and $\mathrm{Li}, 2012)$. In contrast, $\mathrm{MCH}$ neurons are most active during sleep (Hassani et al., 2009), and MCH promotes sleep or physical inactivity (Nahon, 2006; Peyron et al., 2009; Konadhode et al., 2013; Monti et al., 2013), and regulates the autonomic nervous system. Central administration of $\mathrm{MCH}$ via chronic intracerebroventricular infusion (Messina and Overton, 2007) or acute injection into the nucleus of the solitary tract (NTS) (Brown et al., 2007) induces bradycardia and decreases blood pressure. Using a fluorescent-tag to identify LepRb positive neurons, Leinninger and Myers (2008); Leinninger (2011) demonstrated that in the LHA LepRb neurons do not co-express OX or MCH, but rather are co-distributed among the OX neurons (Figure 1). Both LepRb and $\mathrm{OX}$ neurons are surrounded by the $\mathrm{MCH}$-containing neurons in the LHA (Leinninger and Myers, 2008; Leinninger, 2011). In addition, LHA LepRb neurons have direct synapses with OX neurons suggesting an important modulatory relationship between LepRb and OX neurons in LHA (Louis et al., 2010).

\section{OREXIN PROJECTIONS AND OREXIN RECEPTORS}

In contract to the very localized property of the OX neurons, OX axons are widely distributed throughout the CNS, with the exception of the cerebellum (Peyron et al., 1998; Date et al., 1999; Nambu et al., 1999). Based on in situ hybridization both $\mathrm{OX}_{1} \mathrm{R}$ and $\mathrm{OX}_{2} \mathrm{R}$ mRNAs are distributed extensively in the same regions that contain dense OX innervation (Trivedi et al., 1998; Marcus et al., 2001), e.g., the forebrain, the hypothalamus, the brainstem and the spinal cord. Both OX receptors and efferent projections are found in many sites involved in cardiovascular, respiratory and thermo regulation, e.g., the paraventricular nucleus (PVN), NTS, retrotrapezoid nucleus (RTN), locus coeruleus (LC), Kölliker-Fuse nucleus, rostral ventrolateral medulla (RVLM), medullary raphe, lateral paragigantocellular nucleus, midbrain periaqueductal gray, A5 noradrenergic cell group, parabrachial region, area postrema, intermediolateral cell column of the spinal cord and sympathetic pre-ganglionic neurons (Peyron et al., 1998; Trivedi et al., 1998; Date et al., 1999; Nambu et al., 1999; Marcus et al., 2001). In the brainstem, networks of OX-ir fibers and terminals are expressed on the neurons of all major catecholamine cell groups [adrenaline (Adr): C1, C2, and C3 and noradrenaline (NA): locus coeruleus, A1, A2, A4, A5 and A7] (Puskas et al., 2010). Intracerebroventricular (icv) injection of orexin induces $c$-fos expression in the locus ceruleus, arcuate nucleus, central gray, raphe nuclei, NTS, supraoptic nucleus (SON), and PVN in Wistar rats (Date et al., 1999). The widespread nature and specific connections of the orexin system suggests that orexin may be involved not only in the regulation of the sleep-wake cycle and appetite but also autonomic functions, particularly cardiorespiratory functions. Orexin may act to link the regulation of cardiorespiratory functions to wakefulness and sleep.

\section{SUMMARY OF OREXIN NEURONS AND RECEPTORS}

Both orexin projections and orexin receptors are enriched in the neuronal sites that are importantly involved in cardio-respiratory regulation, and they are well positioned to participate in the regulation of cardio-respiratory functions.

\section{THE ROLE OF OREXIN IN CARDIOVASCULAR FUNCTION OREXIN, BLOOD PRESSURE, AND SYMPATHETIC NERVOUS SYSTEM}

The sympathetic nervous system (SNS) plays a crucial role in the regulation of circulation and blood pressure (Guyenet, 2006; Fisher and Paton, 2011; Zubcevic et al., 2011), and many neuronal groups in the lateral hypothaluamus and brainstem are critically involved in such regulation. It is known, that in vivo, electrical or chemical stimulation of the perifornical nucleus of the hypothalamus increases blood pressure and heart rate (HR) and activates neurons of the lateral paragigantocellular area (Sun and Guyenet, 1986; Allen and Cechetto, 1992). Soon after orexin and orexin receptors were discovered in 1998, many studies started to examine if orexin in the LHA participation in the regulation of cardiovascular and sympathetic functions (Samson et al., 1999;

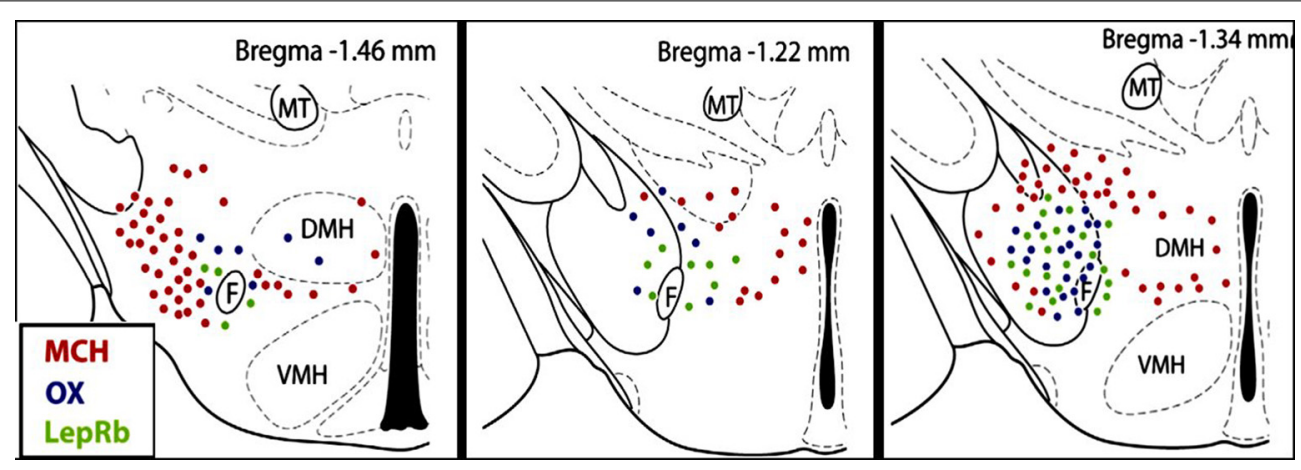

FIGURE 1 | Distribution of orexin (OX), melanin concentrating hormone (MCH) and leptin receptor (LepRb) -expressing neurons in the lateral hypothalamus (LHA). OX, MCH and LepRb-expressing neurons are intermingled in the LHA, but there is no co-expression. Red dots, $\mathrm{MCH}$ neurons; blue dots, OX neurons; green dots, LepRb neurons. F, Fornix; VMH, ventromedial hypothalamus; DMH, dorsomedial hypothalamus; MT, mammillothalamic tract (figure adapted with permission from Leinninger, 2011). 
Shirasaka et al., 1999; Matsumura et al., 2001). In vitro, orexin in a dose-dependent manner, depolarizes neurons that are involved in the regulation of blood pressure and sympathetic nerve activity (SNA), e.g., neurons in the hypothalamic PVN and the RVLM (Shirasaka et al., 2001; Follwell and Ferguson, 2002; Huang et al., 2010), as well as spinal cord sympathetic preganglionic neurons (Antunes et al., 2001). In the RVLM both OX-A and OX-B depolarize neurons in a dose dependent manner, and at $100 \mathrm{nM}$, orexin excited $\sim 42 \%$ of neurons in the area. Application of an $\mathrm{OX}_{2} \mathrm{R}$ antagonist (TCS-OX2-29) significantly reduced the number of neurons activated by $\mathrm{OX}-\mathrm{A}$, while co-application of $\mathrm{OX}_{1} \mathrm{R}$ and $\mathrm{OX}_{2} \mathrm{R}$ antagonists completely eliminated orexin A-induced depolarization (Figure 2) (Huang et al., 2010). Furthermore, about $88 \%$ of adrenergic, $43 \%$ of noradrenergic, and $36-41 \%$ of rhythmically firing RVLM neurons can be excited by orexin in the RVLM (Huang et al., 2010).

Functional studies in vivo have demonstrated that orexin participates in blood pressure regulation. Transgenic orexin deficient animals, both prepro-orexin knockout (pp-OX KO) mice (Figure 3) and rats with orexin neurons-genetically ablated (orexin/ataxin-3), have lower resting blood pressure (Kayaba et al., 2003; Schwimmer et al., 2010) relative to their wild type controls. In both anesthetized and unanesthetized normotensive animals, central administration of OX-A or OX-B activates sympathetic activity and increases both arterial blood pressure (ABP) and HR (Samson et al., 1999; Shirasaka et al., 1999, 2002; Chen et al., 2000; Antunes et al., 2001; Matsumura et al., 2001; Machado et al., 2002; Shahid et al., 2011, 2012). In conscious rats and rabbits (Shirasaka et al., 1999; Matsumura et al., 2001; Samson et al., 2007) central administration (icv) of orexin increases ABP (Samson et al., 1999; Shirasaka et al., 1999; Matsumura et al., 2001), and SNA (Shirasaka et al., 1999; Matsumura et al.,
2001) in a dose dependent manner, and the increased ABP, $\mathrm{HR}$ and SNA induced by orexin is accompanied by an increase in plasma catecholamines (Figure 4) (Shirasaka et al., 1999; Matsumura et al., 2001). Intravenous injection of a ganglionicblocking agent, pentolinium, can abolish OX-A induced increases in $\mathrm{ABP}$ and plasma epinephrine concentrations, which suggests that the pressor response induced by the icv injection of orexinA can be attributed primarily to enhanced sympathetic outflow (Matsumura et al., 2001). Focal injection of OX-A into the RVLM can also induce a significant increase in ABP and HR in both anesthetized (Chen et al., 2000; Shahid et al., 2012) and conscious (Machado et al., 2002) rats. In anesthetized rats, the increased $\mathrm{ABP}$ is accompanied by increased splanchnic SNA(sSNA) and ventilation (phrenic nerve activity) that can be attenuated by blocking $\mathrm{OX}_{1} \mathrm{R}$ (Shahid et al., 2012). The peak effects following OX-A injection into the RVLM were observed at a dose of 50 pmol with $\sim 42 \mathrm{mmHg}$ increase in $\mathrm{ABP}$ and $45 \%$ increase in SNA (Shahid et al., 2012).

Other studies also directly and indirectly support orexin's role in the regulation of blood pressure and SNA, e.g., intrathecal injection of OX-A elicits a dose-dependent increase in ABP, HR (Antunes et al., 2001; Shahid et al., 2011), and sSNA (Shahid et al., 2011), and the effects can be partially attenuated by either betaadrenergic or alpha-adrenergic receptor antagonists (Antunes et al., 2001) or $\mathrm{OX}_{1} \mathrm{R}$ antagonist (Shahid et al., 2011) in anesthetized rats. Microinjection of OX-A into the medullary raphe significantly increases $\mathrm{ABP}, \mathrm{HR}$, and body temperature in unanesthetized rats, (Luong and Carrive, 2012). It is well known that orexins are excitatory neuropeptides that also promote locomotion such as chewing and grooming (Shirasaka et al., 1999; Takakusaki et al., 2005; Thorpe and Kotz, 2005). To exclude the possible effects of increased locomotion on the changes in ABP,

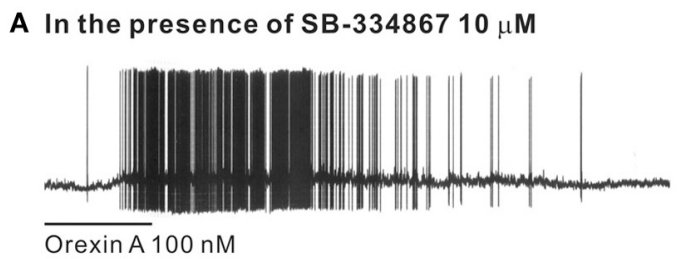

B In the presence of TCS OX2 $2910 \mu \mathrm{M}$

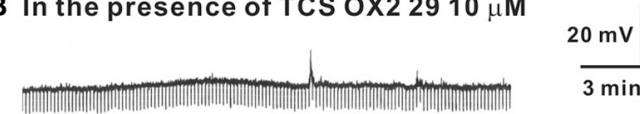

$\overline{\operatorname{Orexin} \mathrm{A}} 100 \mathrm{nM}$

C

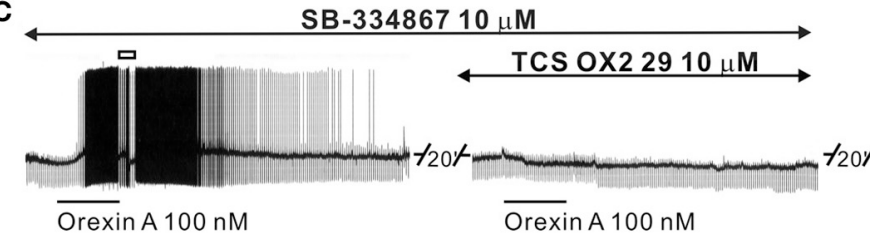

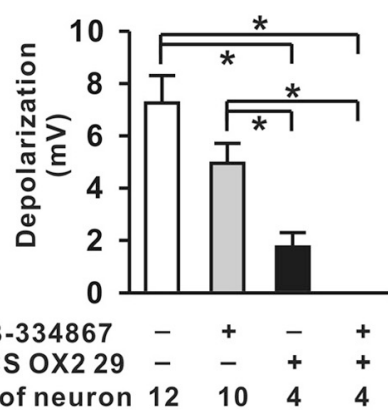

$\begin{array}{ccccc}\text { TCS OX2 } 29 & - & - & + & +\end{array}$

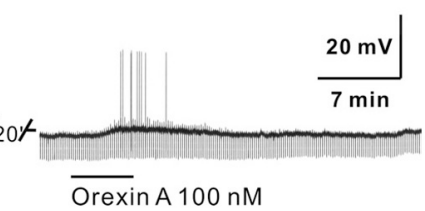

FIGURE 2 | Orexin A excites RVLM neurons in vitro. The OX-A induced depolarization of RVLM neurons (D) was: (1) not significantly affected by $O X_{1} R$ antagonist SB-334867 (A,D), (2) significantly reduced by an $\mathrm{OX}_{2} \mathrm{R}$ antagonist, TCS OX2 29 (B,D), and (3) abolished by simultaneous application of OX1R and OX2R antagonists (C,D). (Figure used with permission from Huang et al., 2010). Values are the mean \pm S.E.M. with the numbers of neurons indicated below each bar. *Significant difference $p<0.05$ (One-Way ANOVA followed by the Student-Newman-Keuls test). 


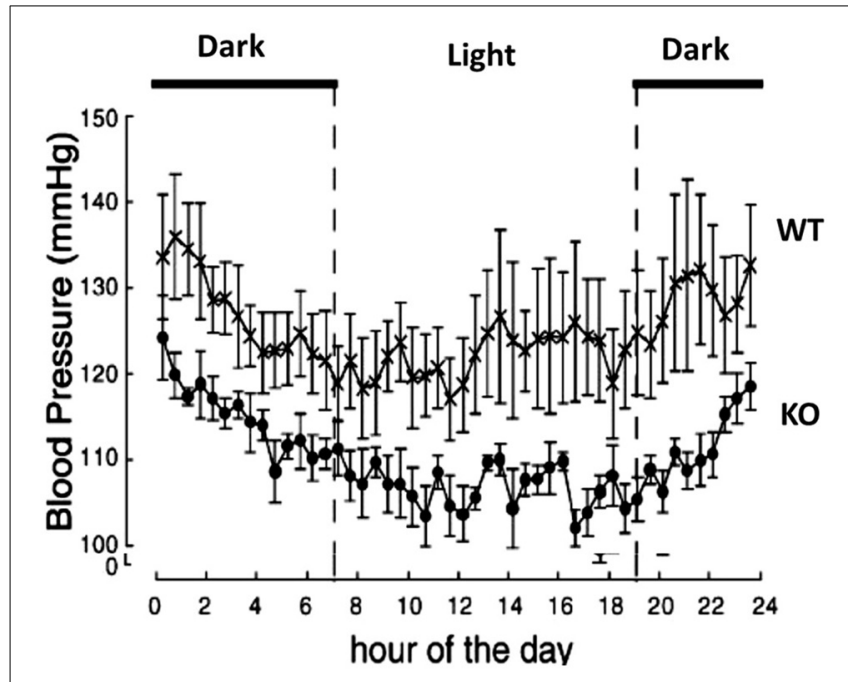

FIGURE 3 | Prepro-orexin knockout mice have lower blood pressures throughout the circadian cycle. The knockout mice have lower blood pressure in both the light and dark periods of the diurnal cycle relative to the wild type control mice. Filled circles: KO mice; crosses: WT mice. (Figure used with permission from Kayaba et al., 2003).

HR and SNA induced by the exogenous orexin in conscious rats, Shirasaka et al. injected OX-A icv in both anesthetized and conscious rats and tested them under the same experimental conditions. They found that OX-A induced a similar significant increase in ABP, HR and SNA in both anesthetized and conscious conditions in these rats (Shirasaka et al., 1999), which suggests that the sympathoexcitatory effects induced by exogenous orexin in the CSN are not due to the activation of locomotion.

Orexin is involved in the cardio-respiratory responses to acute stress, e.g., panic and fear (Kuwaki et al., 2008; Furlong et al., 2009; Iigaya et al., 2012; Johnson et al., 2012; Xiao et al., 2013). For example, in rats, silencing the hypothalamic pp-OX (Hcrt gene) with RNAi or antagonizing $\mathrm{OX}_{1} \mathrm{Rs}$ can block blood pressure and HR responses to acute panic stress (Johnson et al., 2010). And antagonizing both orexin receptors can: (1) significantly reduce the "bicuculline" induced stress responses, e.g., hypertension, tachycardia, and renal sympathoexcitation (Iigaya et al., 2012); (2) decrease the fear induced pressor, tachycardic, and locomotor responses (Furlong et al., 2009); and (3) decrease the hypercapnic-induced respiratory chemoreflex without affecting resting breathing (Li and Nattie, 2010).

In summary, studies in normal animals have shown that the central orexin system participates in regulation of blood pressure, $\mathrm{HR}$, and SNA. Activation of OXRs in the CNS, or only the area of RVLM, by exogenous orexin causes sympathetically mediated hypertension and tachycardia, which can be attenuated by OXR antagonists. Orexin is necessary for blood pressure, HR and SNA responses to certain stresses, e.g., panic and fear.

\section{OREXIN AND HYPERTENSION}

The observations that: (a) orexin participates in the regulation of cardiovascular homeostasis, (b) exogenous orexins can increase SNA and blood pressure in normal animals, and (c) transgenic orexin deficient animals have lower resting blood pressure, have led two independent groups to test the hypothesis that orexin may participate in the development of neurogenic hypertension in spontaneously hypertensive rats (SHRs) (Lee et al., 2013; Li et al., 2013a). The SHR is one of the most studied animal models of neurogenic hypertension. As in human essential hypertension, the blood pressure of the SHR rises with age, starting at about 6 weeks, accompanied by an overactive sympathetic nervous system (Smith and Hutchins, 1979; Zicha and Kunes, 1999; Simms et al., 2009). We found (Li et al., 2013a,b) in unanesthetized freely moving adult SHRs that: (1) there is a strong trend toward a significant increase in orexin-A mRNA expression in the RVLM (Figure 5A), a projection site for orexinergic LHA neurons; (2) blocking both orexin receptors by oral administration of an antagonist, Almxt: (a) significantly lowers blood pressure in wakefulness and sleep during both the dark and light periods of the diurnal cycle, (b) the largest average decrease of $\mathrm{ABP}$ after blocking orexin receptors was in wakefulness during the dark period $(-37 \mathrm{mmHg})$ and the smallest average change in NREM sleep during the light period $(-25 \mathrm{mmHg})$ relative to the pretreatment baseline, (c) one dose of Almxt produced a remarkable and long-lasting $(\sim 8 \mathrm{~h})$ reduction of $\mathrm{ABP}$ in SHRs (Figure 6); (3) the anti-hypertensive effect was accompanied by: (a) a significantly decreased SNA assessed by power spectral analysis of systolic $\mathrm{ABP}$, and (b) decreased noradrenaline levels in cerebrospinal fluid and plasma (Figures 5B,C); (4) antagonizing orexin receptors had no effect on resting blood pressure in normotensive WKY rats (Figure 6B). Our findings are supported by a recent publication (Lee et al., 2013), which showed that blocking $\mathrm{OX}_{2} \mathrm{R}$ centrally by microinjection of an $\mathrm{OX}_{2} \mathrm{R}$ antagonist, TCS-OX2-29, into either the cerebral ventricle (icv) or the RVLM in anesthetized SHRs significantly decreased blood pressure (Figure 7) (Lee et al., 2013). The significant decrease in ABP following TCS-OX2-29 was observed at 3, 10, and $30 \mathrm{nmol}$ doses, and the maximum reduction of $\mathrm{ABP}$ was $\sim 21$ or $\sim 30 \mathrm{mmHg}$ at $30 \mathrm{nmol}$ with icv or RVLM injection respectively. It is important to note that in both studies antagonism of orexin receptor(s) with either Almxt or TCS-OX2-29 had no significant effect on ABP in conscious or anesthetized normotensive Wistar- Kyoto (WKY) control rats.

There are data on cardiovascular effects of the orexin system obtained from transgenic animals and hypertensive animal models that directly and indirectly support an orexin link to hypertension. Two recent genetic analysis studies showed that orexin related genes are altered in both SHRs and mice (Schlager BPH/2J) (Marques et al., 2011a,b; Yamamoto et al., 2013). Like SHRs, the Schlager high blood pressure mouse $(\mathrm{BPH} / 2 \mathrm{~J})$ is a genetic model of neurogenic hypertension. Using affymetrix GeneChip mouse gene arrays Marques et al. (2011b) identified many genes that are differentially expressed in the hypothalamus of the hypertensive mouse relative to the normotensive BPN/3J control mice. Among these altered genes, the pp-OX (Hcrt) gene, which encodes orexin/hypocretin, is significantly increased or upregulated in the hypothalamus in the hypertensive mice. $\mathrm{BPH} / 2 \mathrm{~J}$ hypertensive mice also exhibit a larger variation in ABP between the active and inactive periods of the day relative to the normotensive BPN/3J mice, and GeneChip mouse gene arrays showed 


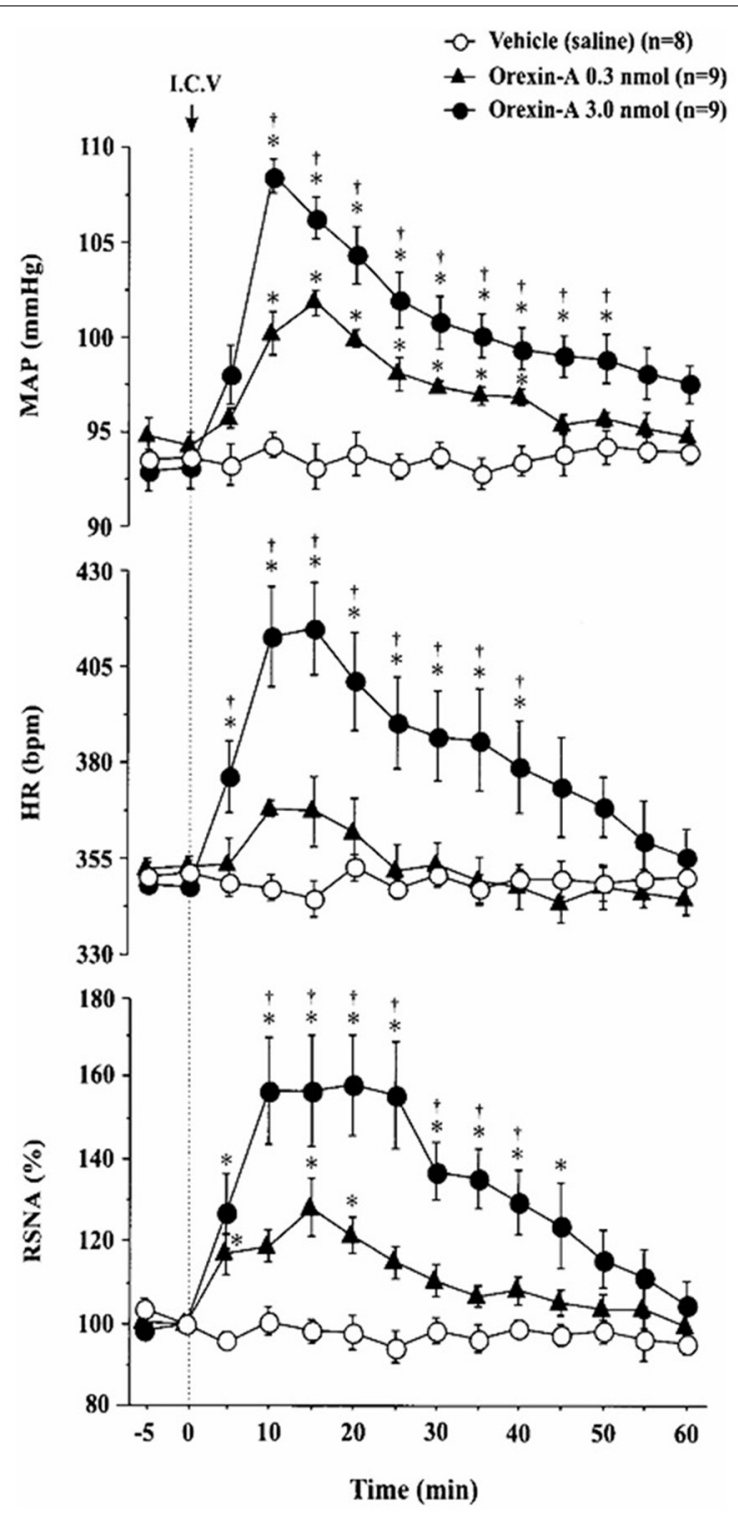

FIGURE 4 | Central application of OX-A increases mean arterial blood pressure (MAP), heart rate (HR) and renal sympathetic nerve activity (RSNA) in conscious rats. Intracerebroventricular injection of OX-A increases MAP, RSNA, HR, and catecholamine release in conscious rats in a dose dependent manner. Orexin-A $(0.3,3.0 \mathrm{nmol})$ provoked an increase in
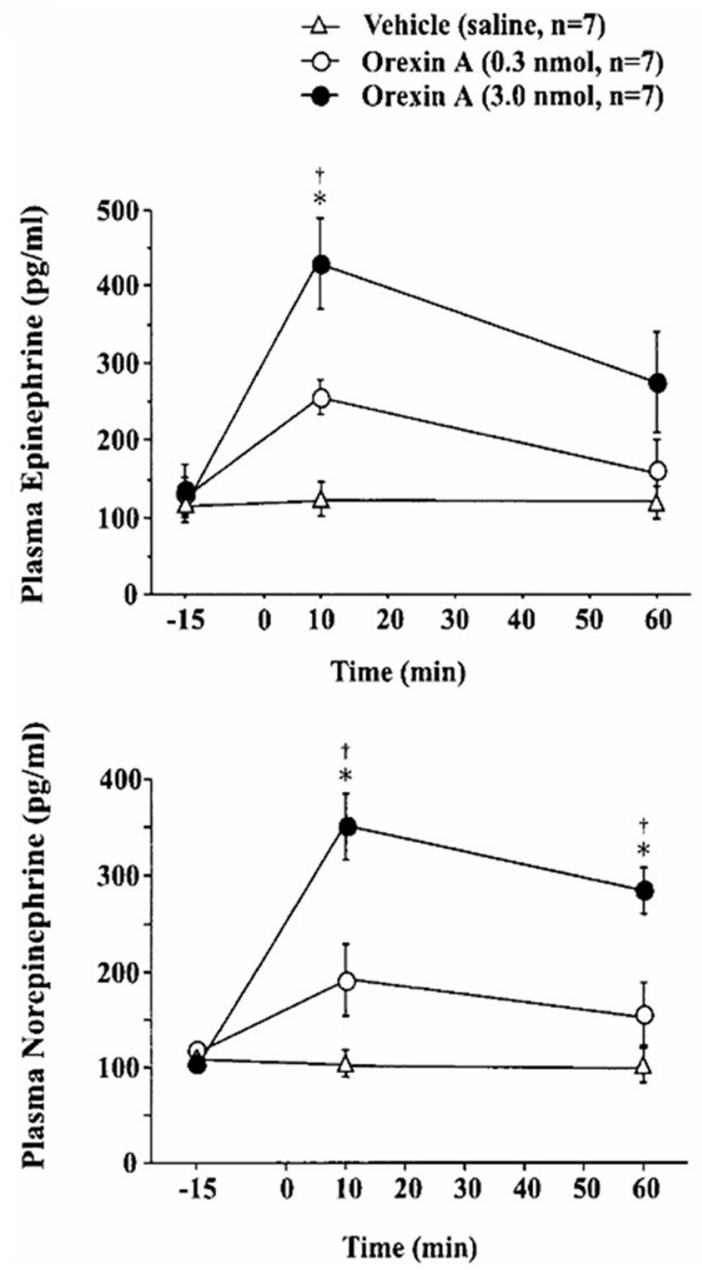

MAP $(94.3 \pm 0.7$ to $101.9 \pm 0.7 \mathrm{mmHg}$ and $93.1 \pm 1.1$ to $108.3 \pm 0.8 \mathrm{mmHg}$, respectively) and RSNA (28.0 \pm 7.0 and $57.9 \pm 12.3 \%)$, respectively. (Figure used with permission from Shirasaka et al., 1999). Left panel: ${ }^{*} P<0.05$ vs. vehicle; ${ }^{\dagger} P<0.05$ vs. orexin-A (0.3 nmol). Right panel: ${ }^{*} P<0.05$ vs. pre-injection values; ${ }^{\dagger} P<0.05$ vs. orexin-A $(0.3 \mathrm{nmol})$. that the $\mathrm{pp}-\mathrm{OX} / \mathrm{Hcrt}$ gene expression is higher during the active period when $\mathrm{ABP}$ is highest than in the inactive period when $\mathrm{ABP}$ is lowest in $\mathrm{BPH} / 2 \mathrm{~J}$ hypertensive mice, and is higher than that of in the normotensive control mice during the same period (Marques et al., 2011a). These genetic and functional studies in the neurogenic hypertensive animal models suggest that an up-regulated or overactive central orexin system may play an important role in developing and maintaining high blood pressure in neurogenic hypertension. It is also interesting to note that Yamamoto et al (Yamamoto et al., 2013) reported that the $\mathrm{OX}_{1} \mathrm{R}$ (Hcrtr1) gene is down-regulated in the adrenal gland in SHR and stroke-prone SHR (SHRSP) relative to normotensive WKY rats. This raises an interesting question of the role of peripheral orexin on cardiovascular function. As mentioned above, orexin neurons are exclusive located in the lateral hypothalamus and send projections to many brain locations. However orexins are found in many peripheral tissues, and the peripheral orexin distributions and functions have been discussed by recent reviews (Kukkonen et al., 2002; Spinazzi et al., 2006; Heinonen et al., 2008; Leonard and Kukkonen, 2013). Orexin receptors have been detected in various peripheral tissues, e.g., the gastrointestinal tract, pancreas, kidney, lung, adrenal gland, and adipose tissue (Kirchgessner and Liu, 1999; Lopez et al., 1999; Johren et al., 2001; Ouedraogo et al., 2003; Heinonen et al., 2008). In rat, both 


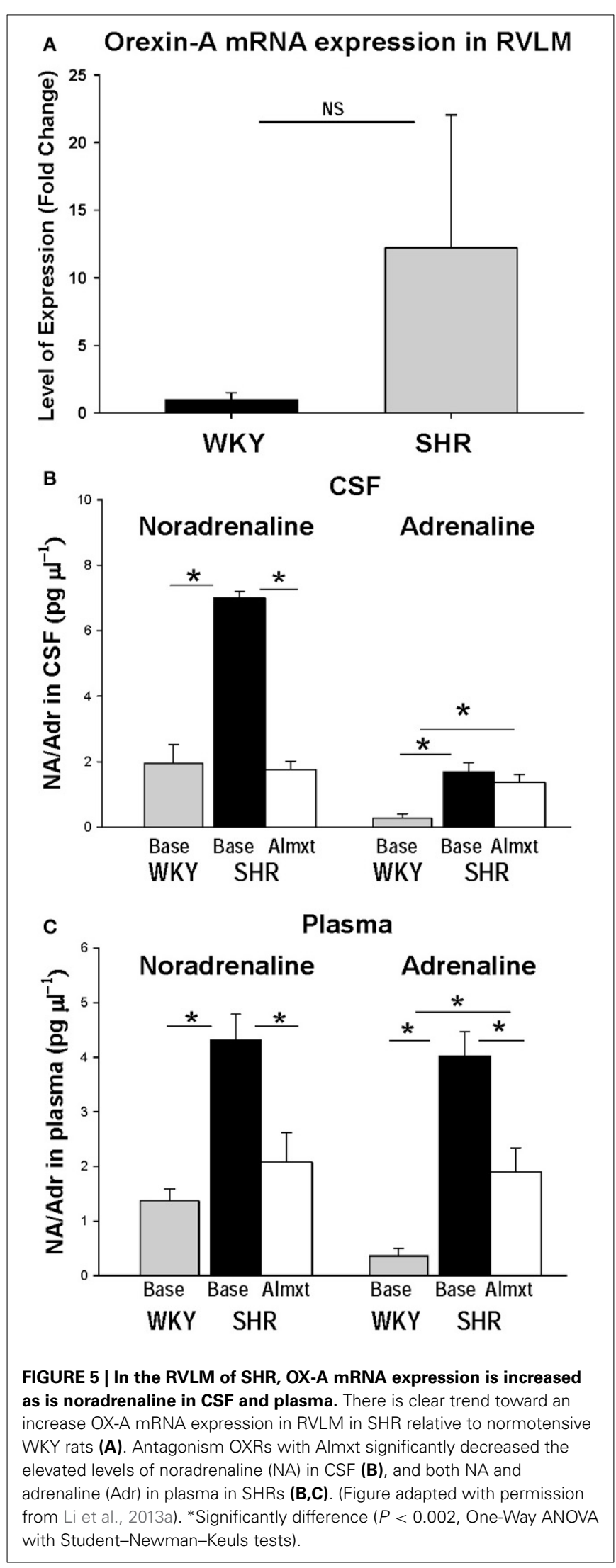

$\mathrm{OX}_{1} \mathrm{R}$ and $\mathrm{OX}_{2} \mathrm{R}$ mRNA can be detected in adrenal gland (Lopez et al., 1999; Johren et al., 2001), and the expression of $\mathrm{OX}_{2} \mathrm{R}$ mRNA in the adrenal is about eight times higher in male than that of female rats (Johren et al., 2001, 2004). The adrenal gland is importantly involved in stress-related cardiovascular function via the hypothalamic-pituitary-adrenal axis, and the significance of a down-regulated Hcrt1R gene in adrenal gland of SHRs needs to be further investigated.

Psychological stresses, e.g., anxiety, prolonged anger, mental stress, have long been considered as a contributing factor in developing hypertension (Zimmerman and Frohlich, 1990; Boone, 1991; Markovitz et al., 1993), and as discussed above orexin is involved in cardiovascular and respiratory responses to the acute stresses, e.g., panic, fear, drug or foot-shock induced, in animal models. Xiao et al. recently investigated possible role of orexin on developing stress related hypertension in adult Sprague-Dawley (SD) rats (Xiao et al., 2013). A stress inducedhypertensive rat (SIHR) was generated by intermittent electric foot-shocks (75-150 V, 0.5 ms duration) every 2-30 s and a buzzer noises $(88-98 \mathrm{~dB})$ for $2 \mathrm{~h}$ twice daily for 14 consecutive days. Adult normotensive SD rats develop hypertension after day 6 under these conditions. Using tail-cuff method the authors found the systolic blood pressure at $2 \mathrm{~h}$ after stress rose from $110 \mathrm{mmHg}$ at baseline to $142 \mathrm{mmHg}$ at day 14 in these SIHRs, and the number of OX-A immunoreactive (OXA-ir) neurons in the LHA and the protein level of $\mathrm{OX}_{1} \mathrm{R}$ in RVLM were significantly greater than that of the control rats. Microinjection of a selective $\mathrm{OX}_{1} \mathrm{R}$ antagonist (SB-408124), or a selective $\mathrm{OX}_{2} \mathrm{R}$ antagonist (TCS OX2 29) into RVLM can partially block the OX-A induced increased SBP and HR in SIHR (Xiao et al., 2013). It is interesting to note that, similar to the neurogenic hypertensive model SHRs, SIHRs also developed an overactive central orexin system. It would be interesting to see if blocking both OXRs by Almxt or a combination of $\mathrm{OX}_{1} \mathrm{R}$ and $\mathrm{OX}_{2} \mathrm{R}$ antagonists can decrease blood pressure between days 6 and 14 in these SIHRs and prevent the development of hypertension.

The potential peripheral effects of orexins on blood pressure and SNA have been investigated (Chen et al., 2000; Matsumura et al., 2001). Intravenous injection of OX-A or OX-B at a dose as high as $11 \mathrm{nmol} / \mathrm{kg}$ had no significant effect on $A B P$, HR or SNA in anesthetized rats and conscious rabbits, which suggests that the orexin effects on ABP, HR, and SNA are mediated primarily through the CNS (Chen et al., 2000; Matsumura et al., 2001). At the present time there is little evidence to support a role for peripheral orexins in the regulation of cardiovascular function (Heinonen et al., 2008; Kukkonen, 2013).

In summary: (1) Transgenic orexin deficient animals have a lower resting blood pressure. (2) Blocking OXRs significantly lowers blood pressure and SNA in adult SHRs. (3) PP-OX mRNA and gene expression are upregulated in the CNS in hypertensive rats and mice. Based on these findings we suggest that an overactive orexin system in the CNS may participate in the pathogenesis and maintenance of high blood pressure in certain forms of hypertension. Further, modulation of the orexin system could be a potential target in treating some forms of hypertension. 


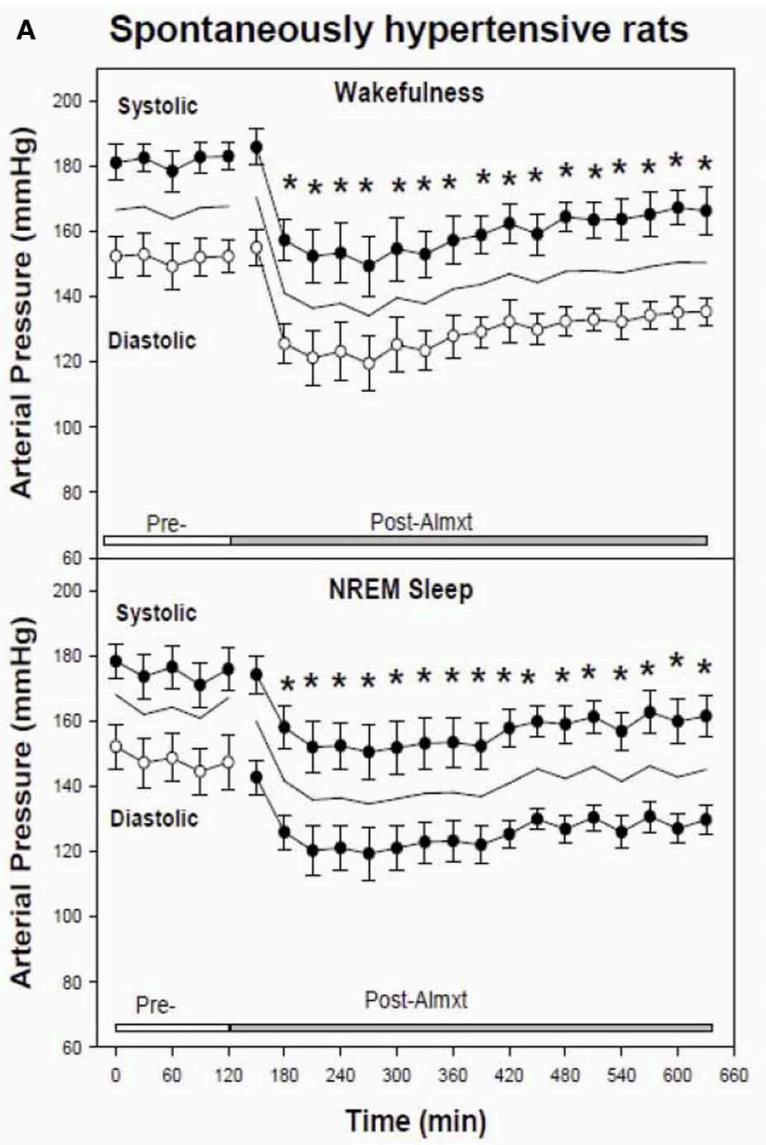

C

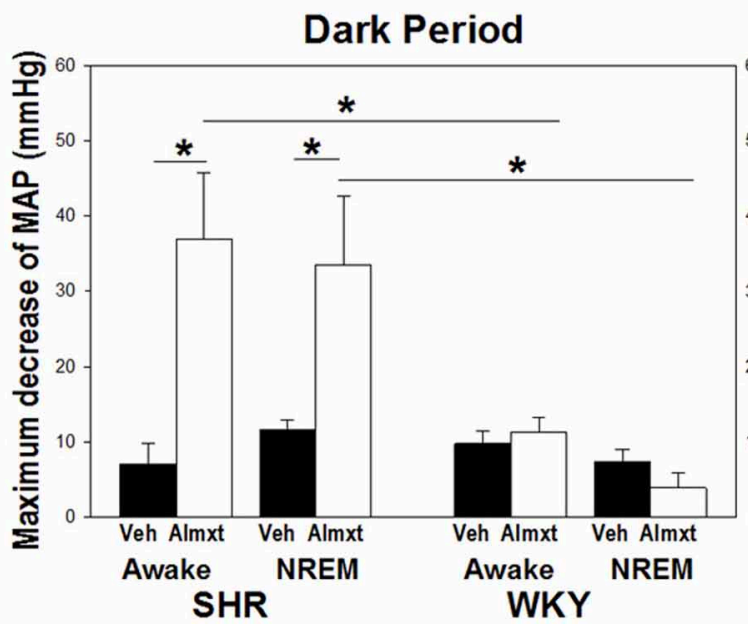

FIGURE 6 | In SHR, antagonism of OXRs with a systemic OXR antagonist, Almxt, decreases arterial pressure. One does of orally administered amlxt significantly decreased arterial pressure in SHR for $\sim 8 \mathrm{~h}$ (A), and Almxt had no effect on arterial pressure in normotensive WKY rats
B Normotensive WKY rats

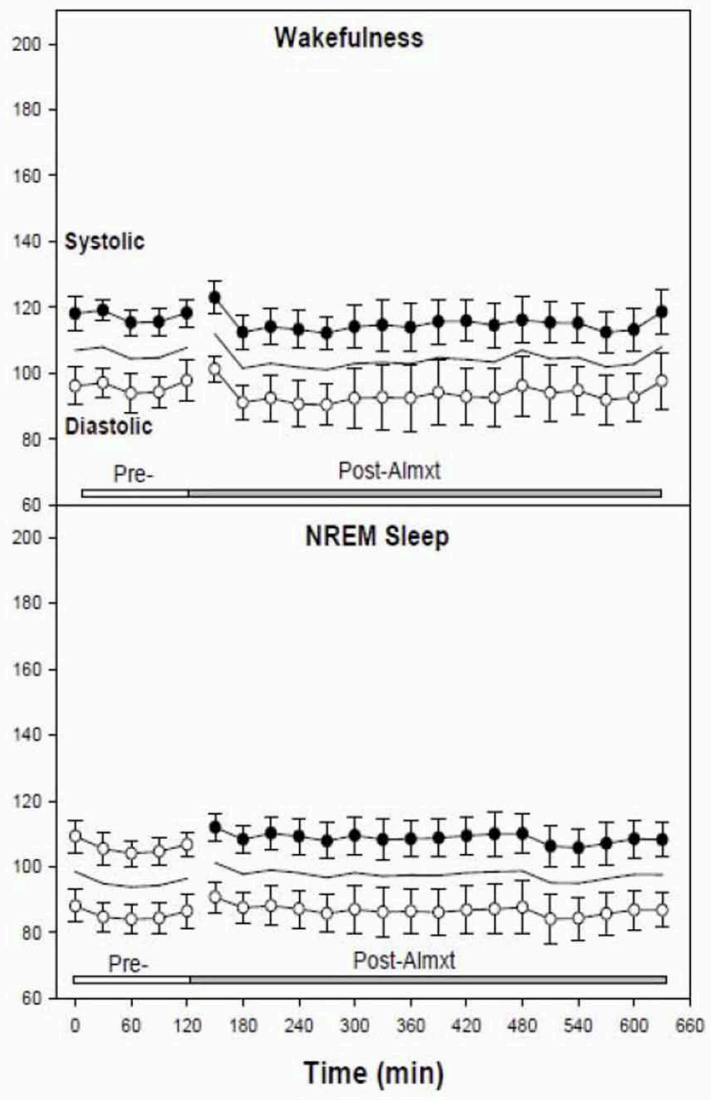

Light Period

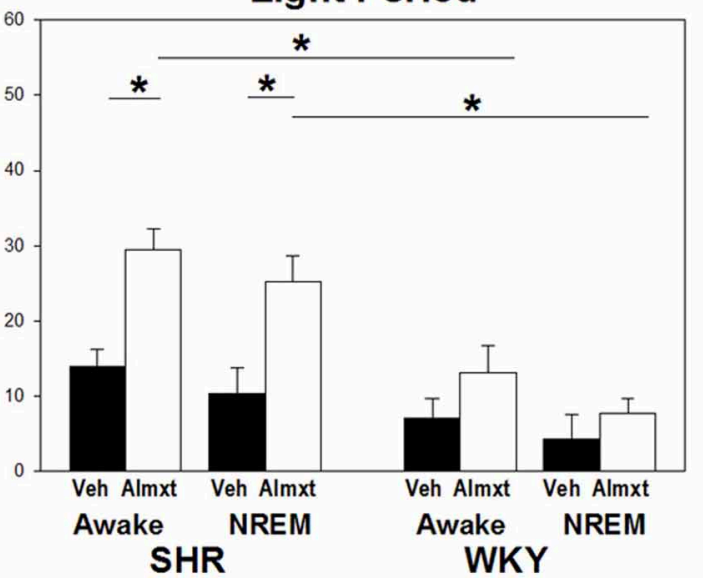

(B). The largest decrease of BP after Almxt is in wakefulness during the dark period $(-37 \mathrm{mmHg}$ ) and smallest change is in NREM sleep during the light period $\left(-25 \mathrm{mmHg}\right.$ ) relative to the pretreatment baseline (C). ${ }^{*} P<0.02$ (Figure adapted with permission from Li et al., 2013a).

\section{SUMMARY OF THE ROLE OF OREXIN IN CARDIOVASCULAR FUNCTION}

In normal animals, activation of OXRs by orexin in the CNS or in areas critically involved in SNA regulation, e.g., the RVLM and spinal cord, induces sympathetically mediated hypertension and tachycardia, which can be attenuated by OXR antagonists. Transgenic orexin deficient animals have a lower resting blood pressure. Spontaneously hypertensive rats and mice may have an overactive orexin system as (1) blocking OXRs produces 


\section{A SHR}
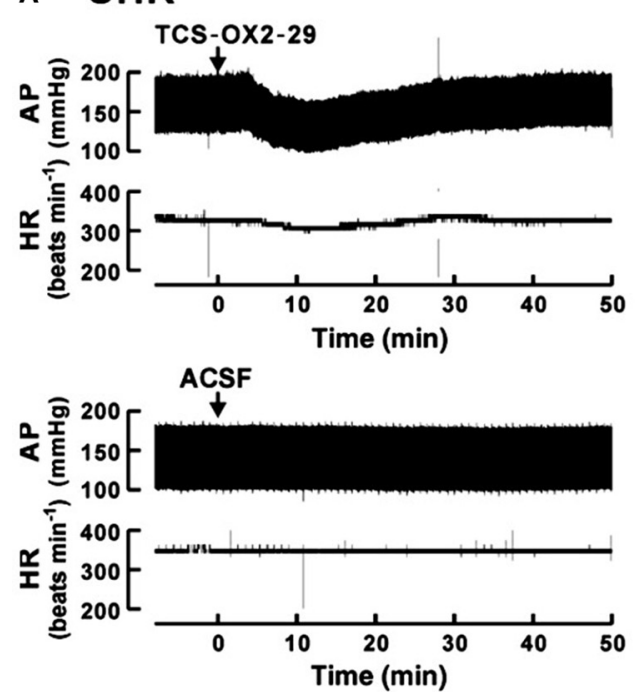

\section{B WKY}
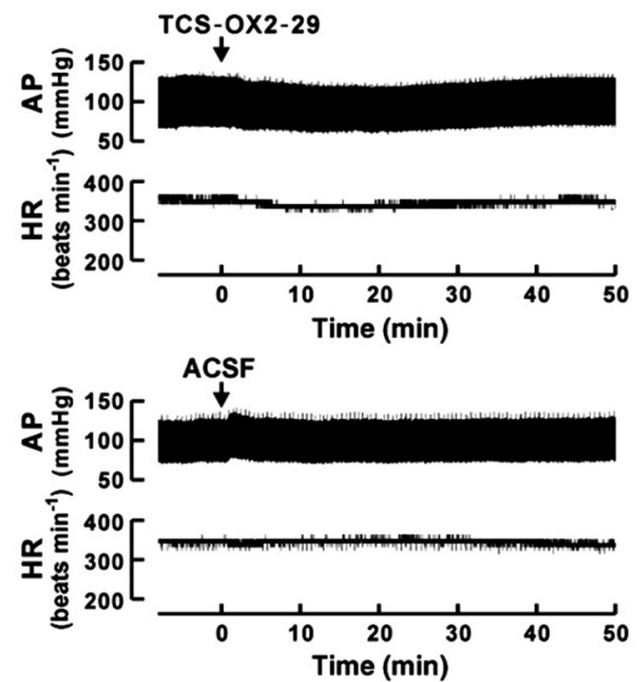

C

\section{$\square$ SHR, ACSF $\square$ WKY, ACSF}

WUSHR, TCS-OX2-29 שWWY, TCS-OX2-29
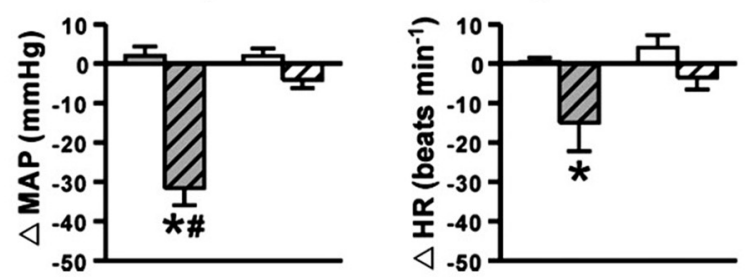

FIGURE 7 | In anesthetized SHR, antagonism of $O X_{2} R$ in RVLM decreases arterial pressure. Microinjection of an $\mathrm{OX}_{2} \mathrm{R}$ antagonist (TCS-OX2-29) into the RVLM significantly decreased mean AP and HR in anesthetized SHR $(\mathbf{A}, \mathbf{C})$, and the maximum change of mean AP and HR being $30 \mathrm{mmHg}$ and $20 \mathrm{bpm}$ respectively (C, gray hatched bars). It is important to note that blocking $\mathrm{OX}_{2} \mathrm{R}$ in RVLM in normotensive WKY rats had no effect on $A B P$ and $H R$ ( $B, C$, white hatched bars). Control vehicle (ACSF) injection had no effect on AP and HR in SHR and WKY rats

(A,B,C). (Figure adapted with permission from Lee et al., 2013).

*,\#Significant difference $(p<0.05)$. significant anti-hypertensive effects in SHRs, (2) the expression of OX-A mRNA in increased in RVLM in SHRs and (3) the pp$\mathrm{OX} / \mathrm{Hcrt}$ gene is upregulated in hypothalamus in hypertensive $\mathrm{BPH} / 2 \mathrm{~J}$ mice. Orexin is important in the regulation of SNA and blood pressure and an overactive orexin system may be pathologically linked to the development of neurogenic hypertension.

\section{OREXIN AND RESPIRATION: THE CENTRAL CHEMOREFLEX AND BLOOD PRESSURE REGULATION} OREXIN, RESPIRATION, AND THE HYPERCAPNIC CHEMOREFLEX

Anatomically the orexin system is well positioned to be involved in the regulation of respiration and central chemoreception. Orexin neurons innervate many brainstem respiratory nuclei including the RTN, medullary raphe, LC, NTS, and pre-Bötzinger complex (Peyron et al., 1998; Date et al., 1999; Kukkonen et al., 2002; Young et al., 2005; Puskas et al., 2010; Lazarenko et al., 2011; Tupone et al., 2011; Nixon et al., 2012). Retrograde tracing studies showed that LHA OX-A positive neurons project to the diaphragm (Young et al., 2005; Badami et al., 2010) and raphe pallidus (Tupone et al., 2011). In Phox2b-eGFP transgenic mice, Lazarenko et al. further showed that the orexin-containing axonal varicosities are closely positioned relative to RTN Phox $2 b$ expressing neurons (Lazarenko et al., 2011). The expression of
$\mathrm{OX}_{1} \mathrm{R}$ and/or $\mathrm{OX}_{2} \mathrm{R}$ mRNA is also found abundantly in many respiratory nuclei in the brainstem with a pattern matching that of OX-containing axon terminals (Marcus et al., 2001; Kukkonen et al., 2002).

At the cellular level, using in vitro patch-clamp recordings in visualized orexin neurons in brain slices, Williams et al., showed that the orexin neurons are intrinsically $\mathrm{CO}_{2}$ (Figure 8A) and $\mathrm{pH}$ (Figure 8B) sensitive (Williams et al., 2007). The orexin neurons in LHA increase their firing rate during acidification and decrease their firing rate during alkalization (Figure 8), while non-orexin neurons are not responsive to such changes (Figure 8C) (Williams et al., 2007). These effects are mediated, at least in part, by the TASK-like tandem-pore $\mathrm{K}^{+}$channels (Williams et al., 2007), and possibly by other acid-sensing channels, e.g., ASICs (Song et al., 2012).

In addition to their intrinsic $\mathrm{CO}_{2} / \mathrm{pH}$ sensitivity, orexin neurons also modulate the activity of brainstem chemosensitive neurons such as those in medullary raphe nuclei and RTN (Dias et al., 2010; Lazarenko et al., 2011; Tupone et al., 2011; Nattie and Li, 2012). Electrophysiological studies in slices from neonatal (P6P10) Phox2b-eGFP transgenic mice showed that orexin A excites the acid sensitive eGFP/Phox $2 \mathrm{~b}$-expressing RTN neurons in a dose dependent manner (ED50 250 nM, Figure 9), and these 


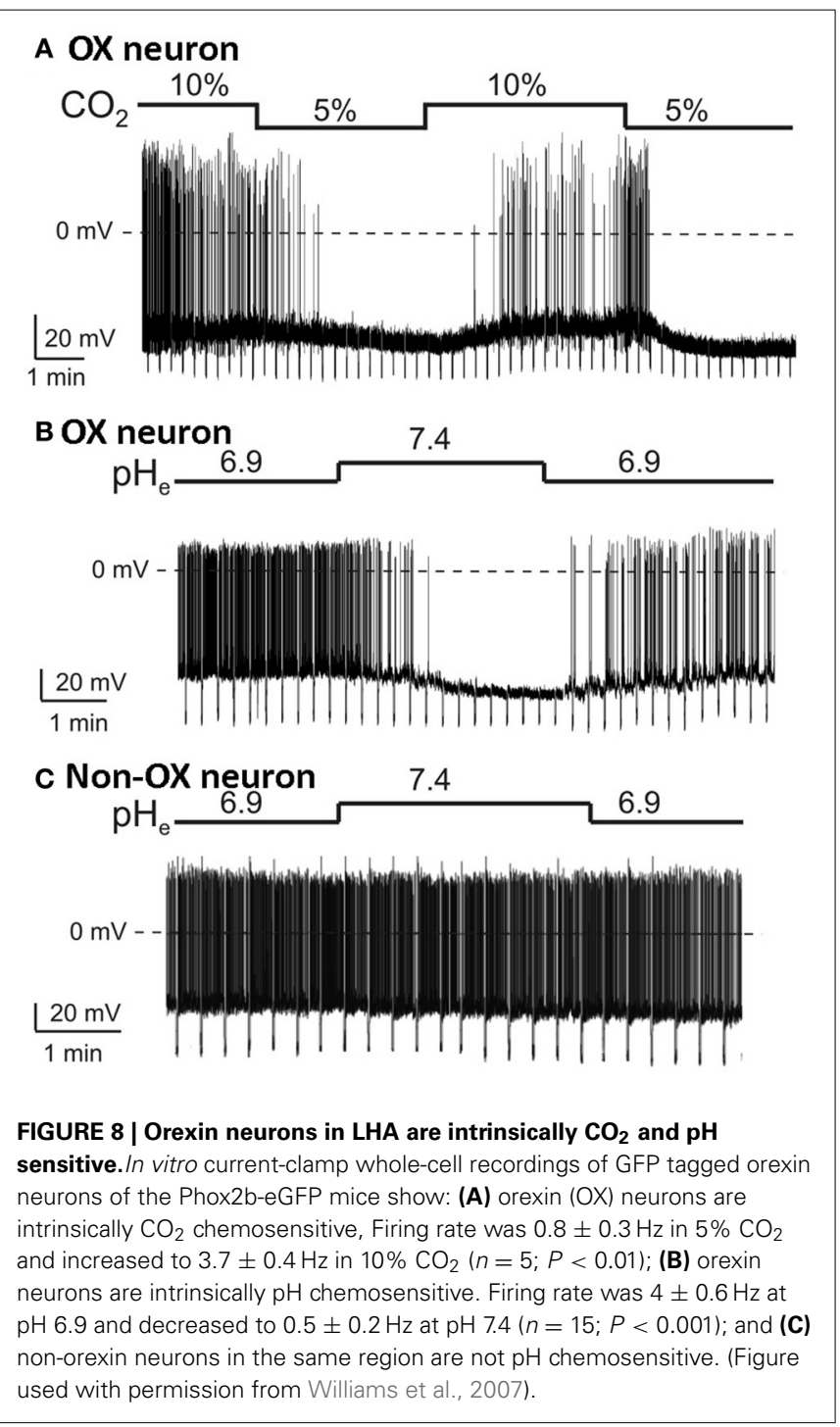

neurons increased activity upon bath acidification, decreased firing with alkalization, and exhibited an $\sim 5 \mathrm{~Hz}$ dynamic range of response between pH 7.0 and 7.5 (Figures 9A,B) (Lazarenko et al., 2011). Functional studies have shown that the orexin system participates in the regulation of respiration and the $\mathrm{CO}_{2}$ central chemoreflex (Dutschmann et al., 2007; Nakamura et al., 2007; Williams et al., 2007; Dias et al., 2009, 2010; Li and Nattie, 2010; Lazarenko et al., 2011). Microinjection of orexin into the RVLM at the level of the pre-Bötzinger complex causes a significant increase in amplitude of integrated phrenic nerve activity (an index of tidal volume) in anesthetized and vagotomized rats (Young et al., 2005; Shahid et al., 2012). Injection of OX-B into the Kölliker-Fuse nucleus significantly increases breathing frequency in P21-42 day rats using the intra-arterially perfused working heart-brainstem preparation (Dutschmann et al., 2007). In the decerebrate cat, OX-A application into the hypoglossal motor nucleus increases genioglossus muscle activity (Peever et al., 2003). The pp-OX knockout mouse with a complete lack of orexin has normal resting breathing but a significantly attenuated respiratory chemoreflex in wakefulness compare to the wide type control mice and supplementation of orexins can partially restore the reflex (Deng et al., 2007; Nakamura et al., 2007). Unilateral administration of an $\mathrm{OX}_{1} \mathrm{R}$ antagonist (SB334867) in the RTN significantly reduced the respiratory response to hypercapnia $\left(7 \% \mathrm{CO}_{2}\right)$ with a substantial effect in wakefulness $(-30 \%$; Figure 10A) and a much smaller effect in sleep (-9\%) (Dias et al., 2009). In the medullary raphe, inhibition of the $\mathrm{OX}_{1} \mathrm{R}$ produced a significant reduction of the $\mathrm{CO}_{2}$ chemoreflex in wakefulness ( $-16 \%$; Figure 10B) but not in sleep (Dias et al., 2010). Antagonism both $\mathrm{OX}_{1} \mathrm{R}$ and $\mathrm{OX}_{2} \mathrm{R}$ by orally administrating a dual OXR antagonist, Almxt, significantly decreased the hypercapnic chemoreflex only in wakefulness during the dark period of diurnal cycle $(-31 \%)$; the $\mathrm{CO}_{2}$ chemoreflex was not significantly changed in sleep in the dark period and wakefulness and sleep in the light period of the diurnal cycles (Figure 11) (Li and Nattie, 2010). Antagonism of orexin receptors had no effect on resting breathing (Dias et al., 2009, 2010; Li and Nattie, 2010).

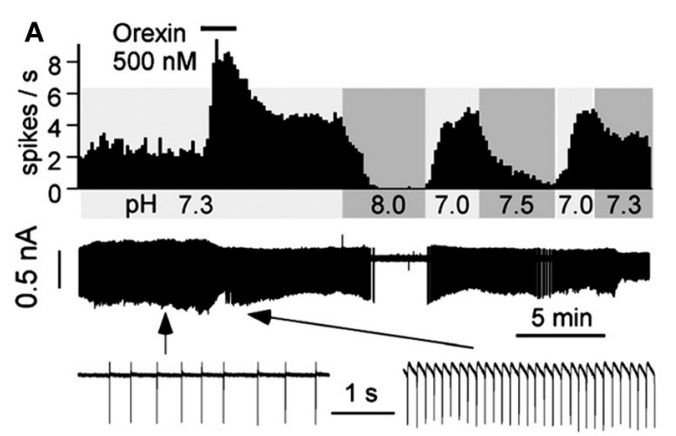

B

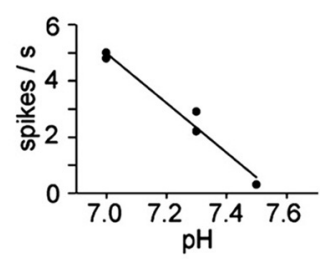

FIGURE 9 | Orexin A excites acid sensitive eGFP/Phox2b-expressing RTN neurons in vitro. Electrophysiological recordings in slices from neonatal (P6-P10) Phox2b-eGFP mice show that OX-A excited eGFP-expressing RTN neurons in a dose-related manner (A). The neuron increased activity upon bath acidification, decreased firing with alkalization with an $\sim 5 \mathrm{~Hz}$ dynamic range of response between $\mathrm{pH} 7.0$ and 7.5 (A,B). (Figure used with permission from Lazarenko et al. 2011). 

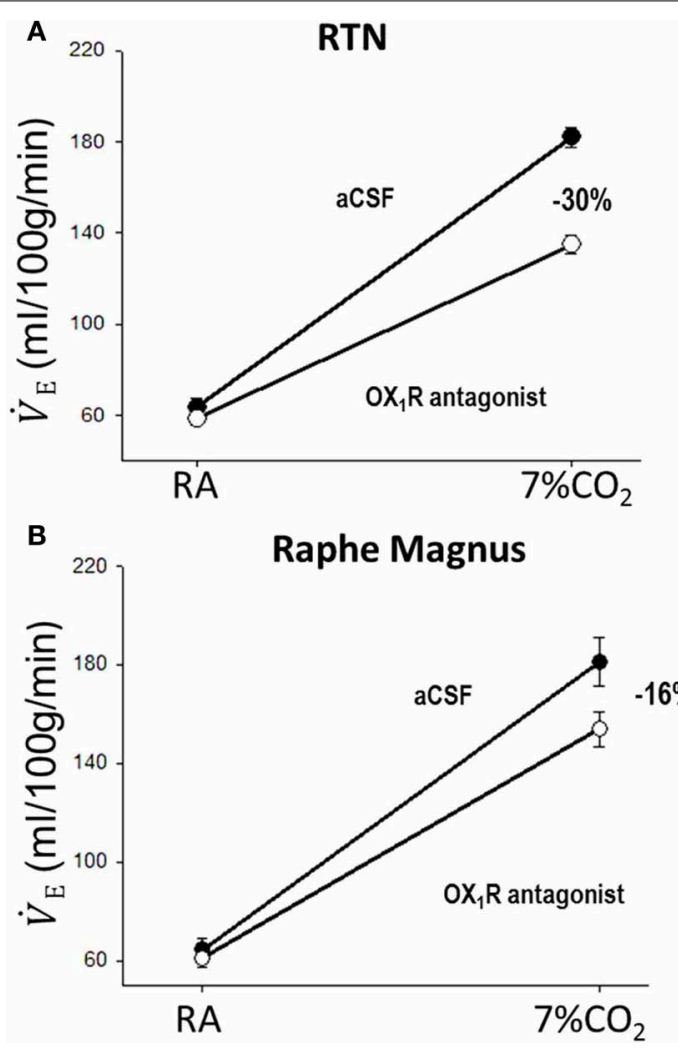

FIGURE 10 | Focal application of an $O X_{1} R$ antagonist in the RTN and the medullary raphe magnus decreases the $\mathbf{C O}_{\mathbf{2}}$ chemoreflex. Inhibition of $O X_{1} R$ in the region of RTN (unilateral, $\mathbf{A}$ ) or raphe magnus $(\mathbf{B})$ by an $\mathrm{OX}_{1} \mathrm{R}$ antagonist (SB334867) significantly decreased the $\mathrm{CO}_{2}$ chemoreflex by 30 or $16 \%$ respectively in wakefulness. (Figure adapted with permission from Dias et al., 2009 and Dias et al., 2010).

These in vitro and in vivo experiments demonstrate that the orexin system is significantly involved in the control of breathing, particularly in the central $\mathrm{CO}_{2}$ chemoreflex.

In summary: (1) Orexin neurons are intrinsically chemosensitive and send projections to other central chemoreceptor sites, e.g., the RTN and medullary raphe. (2) Orexin may regulate breathing and central chemoreception directly and/or indirectly by recruiting other brainstem chemoreceptor sites, e.g., the RTN and medullary raphe. (3) Orexin modulation of the $\mathrm{CO}_{2}$ chemoreflex may be vigilance state dependent with the strongest effect being during wakefulness in the dark period. (4) Orexin may be a link between breathing and sleep-wake status.

\section{RESPIRATION AND CENTRAL CHEMORECEPTION IN BLOOD PRESSURE REGULATION}

\section{Respiration, sympathetic activity, and blood pressure}

Anatomically, many cardiovascular and respiratory related nuclei are closely intertwined within similar regions of the brain, or are even synaptically connected. Many of these nuclei are part of the respiratory-sympathetic network that is critical to the regulation of respiratory and sympathetic activity and blood pressure (Rosin et al., 2006; Zoccal et al., 2009a; Geerling et al., 2010; Guyenet et al., 2010). For example, in the brainstem, both the

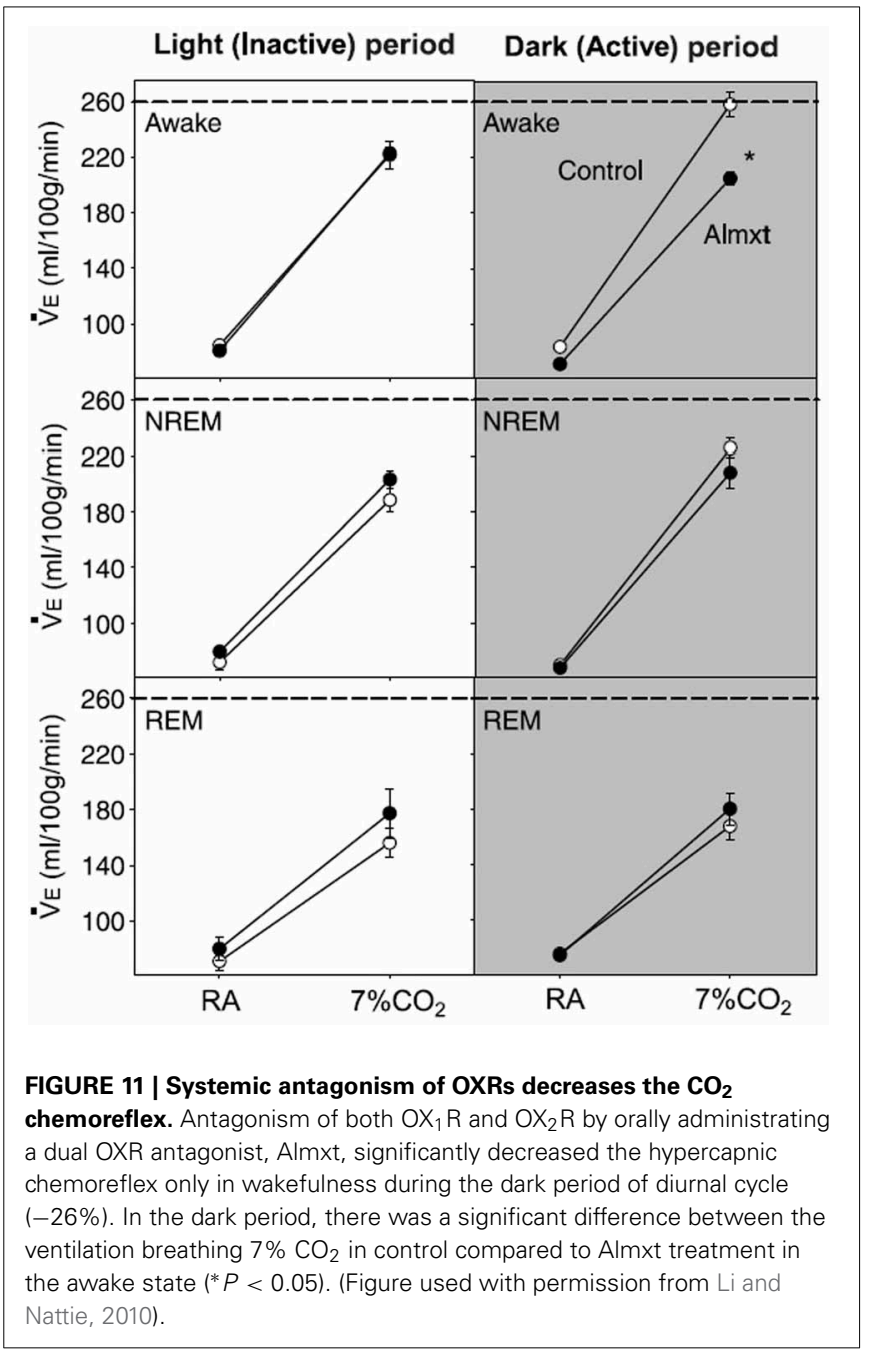

RVLM and the caudal ventrolateral medulla (CVLM), sites critically involved in the regulation of sympathetic tone, overlap with the ventral respiratory column including Bötzinger and preBötzinger neurons. The neurons in the RTN, a putative central chemoreceptor site, innervate the entire ventrolateral medulla including the ventral respiratory column (VRC) and areas critically involved in the ABP and SNA regulation, e.g., the RVLM and CVLM (Rosin et al., 2006). The hypothalamic PVN, an important site for autonomic and endocrine homeostasis, is anatomically connected with many putative central chemoreceptors sites, e.g., the RTN, LC, NTS and medullary raphe (Geerling et al., 2010). The sympathetic preganglionic neurons (SPGNs) in the spinal cord receive prominent innervation from spinal interneurons, the RVLM, the midline medulla oblongata including medullary raphe serotonergic neurons, the pontine A5 noradrenergic cell group, the dorsolateral pons, the hypothalamic PVN, and the orexinergic neurons in the LHA (Jansen et al., 1995). The complex anatomical connections between the respiratory sites, central chemoreceptor sites and cardiovascular regulation sites suggest that the central respiratory chemoreflex is positioned to participate in the regulation or modulation of sympathetic activity and blood pressure. 


\section{Central chemoreception, SNA and blood pressure}

Activation of central chemoreceptors by $\mathrm{CO}_{2} / \mathrm{H}^{+}$increases $\mathrm{ABP}$ and SNA in both humans and experimental animals (Hanna et al., 1981; Lioy and Trzebski, 1984; Somers et al., 1989; Nattie et al., 1992, 1993; Oikawa et al., 2005; Guyenet et al., 2010). In humans, hyperoxic hypercapnia $\left(7 \% \mathrm{CO}_{2} / 93 \% \mathrm{O}_{2}\right)$ induced greater increases in ventilation $\left(\dot{V}_{E}\right)$, blood pressure and SNA than did hypoxia $\left(10 \% \mathrm{O}_{2} / 93 \% \mathrm{~N}_{2}\right)$ (Somers et al., 1989). In conscious rats (Figure 12), Oikawa et al. (2005) showed that hypercapnia induced significant increases in mean ABP, RSNA, and the respiratory rate (Figure 12B) in intact animals and in animals with varied peripheral chemoreceptor input, e.g., carotid body destroyed (CBD), aortic nerve denervated $(\mathrm{AD})$, carotid body destroyed plus aortic denervated (CBAD), and sinoaortic denervated (SAD) (Figure 12C). There were also no significant differences in the magnitudes of increase in ABP and RSNA during hypercapnia between the intact and the chemodenervated groups (Figure 12). The fact that the increased ABP and rSNA response to hypercapnia was not affected by bilateral carotid chemo-denervation, aortic denervation, or sinoaorticdenervation suggests that the peripheral chemoreceptors do not play a major role in the cardiovascular response to hypercapnia in normal conscious rats (Oikawa et al., 2005). Blockade of glutamate receptors in the RTN or lesion of the rostral part of the RVLM decreased respiratory (phrenic nerve activity, PNA) and SNA responses to hypercapnic stimulation in decerebrate, paralyzed, vagotomized, and servo-ventilated cats (Nattie et al., 1992, 1993).

In summary: (1) Many putative central chemoreceptors sites, e.g., the RTN, NTS and medullary raphe, are involved in the regulation of SNA and blood pressure. (2) Activation of central chemoreceptors by hypercapnia significantly increases blood pressure, SNA and respiration with and without peripheral chemoreceptors. These studies suggest that the hypercapnic induced increase in ABP is due to sympatho-excitation via activation of the central chemoreceptors. The central chemoreceptors directly or indirectly regulate sympathetic vasomotor tone and blood pressure, and can activate the sympathetic outflow in a tonic manner independent of the effects on the central respiratory pattern generator (Moreira et al., 2006; Guyenet et al., 2010).

\section{SUMMARY OF OREXIN AND RESPIRATION: THE CENTRAL CHEMOREFLEX AND BLOOD PRESSURE REGULATION}

Orexin neurons are intrinsically chemosensitive and their projections and receptors are found densely in all the major respiratory neuronal groups and central chemoreceptor sites. Activation of central chemoreceptors with and without activation of peripheral chemoreceptors leads to significant sympathoexcitation and hypertension in both human and experimental animals. Respiration and the central chemoreflex are involved in regulation of SNA and blood pressure.

\section{OREXIN, CHEMOREFLEX, AND HYPERTENSION}

Overactive vasoconstrictor sympathetic tone, an enhanced peripheral chemoreflex, and an impaired baroreflex have been found in a significant portion of patients with primary hypertensive as well as in SHRs (Izdebska et al., 1982; Simms et al.,
2009; Tan et al., 2010). In susceptible individuals, stress or altered physiology initiates increases in sympathetic activity to cardiovascular resistance vessels accompanied by increases in blood pressure. Over time, vascular smooth muscle in resistance vessels hypertrophies resulting in persistent hypertension. The SHR is one of the most used animal models of neurogenic hypertension and SHRs develop hypertension at about 6 weeks of life. Using the working heart-brainstem preparation, Simms et al., showed that the respiratory related sympathetic tone is significantly higher in SHRs relative to normotensive WKY rats starting from postnatal day 9-16, well before the onset of hypertension (Simms et al., 2009). They suggest that this augmented respiratory-sympathetic coupling in SHR and its effect on the vascular tone in early life is a causal factor in developing hypertension (Simms et al., 2009, 2010). However, the mechanisms leading to such changes remain unclear at present time.

\section{PERIPHERAL CHEMOREFLEX AND HYPERTENSION}

A link between neurogenic hypertension and an enhanced carotid body chemoreflex has been more extensively studied in patients and in animal models of sleep apnea (Fletcher et al., 1992; Lesske et al., 1997; Fletcher, 2001; Prabhakar et al., 2001, 2005, 2012; Schultz et al., 2007; Simms et al., 2010; Zoccal and Machado, 2011; Costa-Silva et al., 2012; Moraes et al., 2012a,b; Paton et al., 2013). The peripheral chemoreceptor reflex response has been shown to be significantly enhanced in patients with primary hypertension (Trzebski et al., 1982; Tafil-Klawe et al., 1985a,b; Somers et al., 1988a,b; Sinski et al., 2012) and in animal models of systemic hypertension, e.g., SHRs (Fukuda et al., 1987; Simms et al., 2009; Tan et al., 2010). Rats exposed to chronic intermittent hypoxia $(\mathrm{CIH})$ develop hypertension and persistent sympathetic activation, and elimination of the carotid bodies prevents such $\mathrm{CIH}$-induced hypertension (Fletcher et al., 1992; Lesske et al., 1997). Enhanced carotid body activity has been suggested to result in alterations in respiratory-sympathetic coupling (Simms et al., 2009; Zoccal et al., 2009b) and increased muscle vasoconstrictor activity, which may contribute to the development of hypertension (Trzebski et al., 1982; Somers et al., 1988a). The hyperactive carotid chemoreceptors are accompanied by overexpression of ASIC/TASK (acid-sensing ion channel/2-pore domain acid-sensing $\mathrm{K}^{+}$channel) channels in young pre-hypertensive SHRs (Tan et al., 2010). Abdala et al., further showed that bilateral denervation of the carotid sinus nerves (CSD) in SHRs can significantly lower the resting blood pressure $(\sim 25 \mathrm{mmHg})$, respiratory frequency (transiently) and the low frequency component of the frequency analysis of systolic blood pressure, an index of sympathetic vasomotor tone (Figure 13), and they suggested that the inputs of carotid sinus nerve from the carotid body are partially responsible for increased SNA and blood pressure in SHR (Abdala et al., 2012).

In summary: an enhanced peripheral chemoreceptor reflex is found in both human hypertension and SHRs, and bilateral denervation of the carotid sinus nerves can partially lower blood pressure in SHRs. It is suggested that this enhanced carotid body activity may contribute to the alterations in respiratorysympathetic coupling in SHRs. 


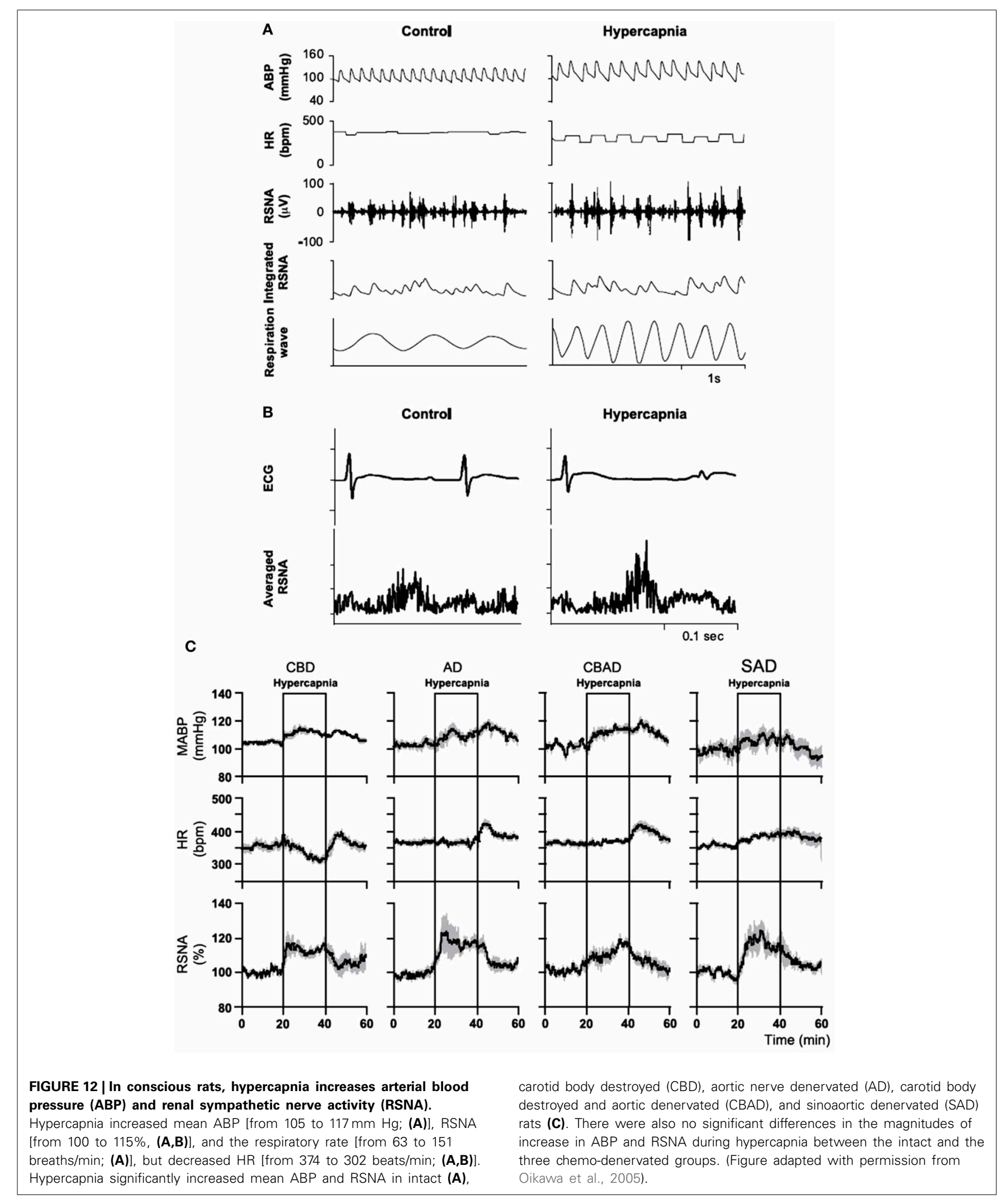




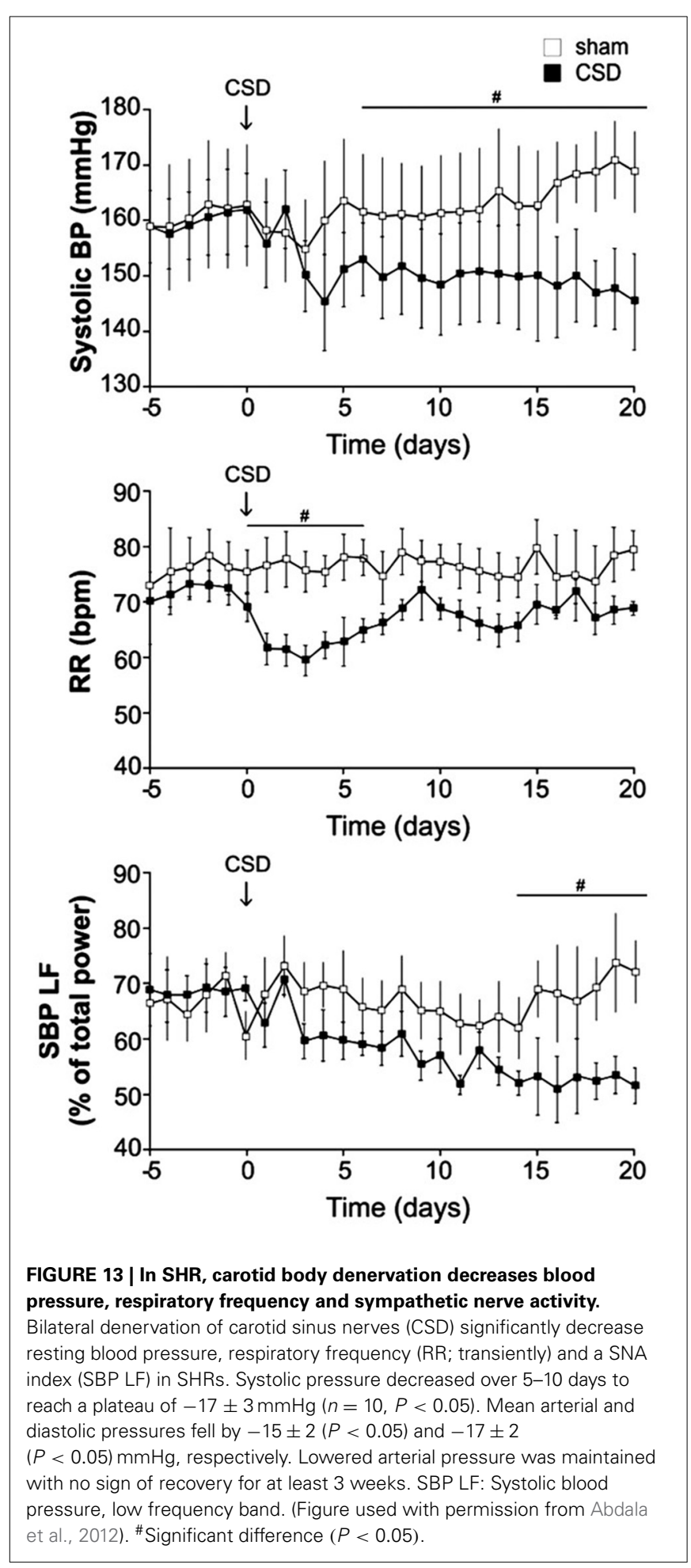

\section{CENTRAL $\mathrm{CO}_{2}$ CHEMORECEPTION, HYPERTENSION}

As discussed above it is well established that activation of central chemoreceptors by $\mathrm{CO}_{2}$ increases breathing, SNA and blood pressure in humans and in anesthetized and conscious animals (Hanna et al., 1981; Lioy and Trzebski, 1984; Somers et al., 1989; Nattie et al., 1992, 1993; Oikawa et al., 2005; Guyenet et al., 2010). In asphyxia, the hypercapnic component is of greater importance than the hypoxic component in causing sympathetically induced increases in ABP and vascular resistance (Morgan et al., 1995; Cooper et al., 2004). However, the links between neurogenic hypertension and the hypercapnic central chemoreflex are not well understood. In human subjects, the hypoxic component of asphyxia reduces the baroreceptor-vascular resistance reflex sensitivity, while the hypercapnic component is responsible for increasing blood pressure (Cooper et al., 2004, 2005). Thus, the effects of both peripheral and central chemoreceptors may contribute to promoting hypertension in patients with obstructive sleep apnea who undergo repeated bouts of asphyxia nightly (Cooper et al., 2005). Combined hypoxia and hypercapnia evoke longer-lasting sympathetic activation in humans than does either hypoxia or hypercapnia alone (Morgan et al., 1995). In patients with heart failure, the central chemoreflex response to hypercapnia is markedly and selectively enhanced (Kara et al., 2003; Yamada et al., 2004), and the enhanced hypercapnic chemosensitivity is correlated significantly with plasma norepinephrine levels suggesting sympathoexcitation (Kara et al., 2003). Administration of $100 \%$ oxygen does not lower sympathetic activity in patients with heart failure, providing further evidence against any peripheral chemoreflex potentiation (Kara et al., 2003). In anesthetized SHRs with carotid sinus denervation, systemic hypercapnia increased and hypocapnia decreased the magnitude of both phrenic and sympathetic discharges, and the increased sympathetic discharge during hypercapnia was accompanied by a significant increase in ABP (Czyzyk-Krzeska and Trzebski, 1990).We have recently reported that SHRs have a significantly augmented central hypercapnic chemoreflex relative to the normotensive WKY control rats ( $\mathrm{Li}$ and Nattie, Neuroscience, 2012). In SHRs, the ventilatory response to normoxic hypercapnia $\left(7 \% \mathrm{CO}_{2} / 21 \% \mathrm{O}_{2}\right)$, or hyperoxic hypercapnia $\left(7 \% \mathrm{CO}_{2} / 93 \% \mathrm{O}_{2}\right)$ when peripheral chemoreceptors are suppressed, is significantly higher in both wakefulness and sleep than that of the normotensive WKY control rats ( $\mathrm{Li}$ and Nattie, Neuroscience, 2012). It is interesting to note that both peripheral and central chemoreflexes have powerful effects on sympathetic activity (see above), and in SHRs both the peripheral and central chemoreflex are overactive. Asphyxia, a recurring condition in sleep disorders, includes two important components, hypoxia and hypercapnia, which are primarily detected by peripheral and central chemoreceptors, respectively, in normal conditions. Sleep disorders are present in $\sim 40 \%$ of obese individuals and both sleep disorders and obesity are closely associated with hypertension (Chau et al., 2012). Many studies have focused on the hypoxic effects of sleep disorders and hypertension with little attention to the role of the central $\mathrm{CO}_{2}$ chemoreflex in sleep disorders and their link to the development of hypertension. It is also interesting to note that while denervation of the peripheral chemoreceptor in SHRs significantly lower ABP (up to $\sim 25 \mathrm{mmHg}$ ), ABP remains significantly above the normal even at 21 days post CSD (Abdala et al., 2012) suggesting other possible mechanisms are involved, e.g., an overactive central chemoreflex.

In summary: in SHRs, the respiratory chemoreflex to hypercapnia is exaggerated with and without peripheral carotid chemoreceptor inputs. 


\section{OREXIN, CENTRAL CHEMORECEPTORS, AND HYPERTENSION}

That activation of orexin receptors evokes increases in breathing, SNA, and ABP, and that SHRs have augmented central and peripheral chemoreflexes suggest that orexin is a key factor that links the cardiovascular and respiratory systems, and that alterations of the orexin system may contribute to some cardio-respiratory diseases. The following observations support this proposed link: (1) The orexin knockout mouse has a decreased respiratory hypercapnic chemoreflex as well as a lower resting ABP (Kayaba et al., 2003; Nakamura et al., 2007). (2) Orexin injections into the CNS increase ABP, HR, SNA, and breathing in both conscious and anesthetized normotensive animals (Shirasaka et al., 1999; Machado et al., 2002; Huang et al., 2010; Shahid et al., 2011, 2012). (3) The SHRs have: (a) an augmented respiratory-sympathetic coupling in reduced preparations (Simms et al., 2009), (b) a hyperactive peripheral chemoreflex (Zoccal et al., 2008; Simms et al., 2009), and (c) a hyperactive central $\mathrm{CO}_{2}$ chemoreflex (Li and Nattie, Neuroscience, 2012). (4) Blockade of both OXRs can significantly lower ABP, HR, SNA and the hyperactive central $\mathrm{CO}_{2}$ chemoreflex in conscious SHRs (Li et al., 2013a). Based on these data, we pose the following questions: (1) What is the role of overactive central chemoreceptors in developing hypertension? (2) What is the role of orexin in this augmented $\mathrm{CO}_{2}$ chemoreflex and hypertension? (3) Can antagonism of OXRs be a target to treat such an augmented $\mathrm{CO}_{2}$ response and the associated hypertension in SHR? At present, we have found that antagonism of both OXRs using an orally administered dual orexin receptor antagonist, Almxt: (1) significantly reduced the exaggerated $\mathrm{CO}_{2}$ chemoreflex in SHR to the same level as measured in the control normotensive WKY rats ( $\mathrm{Li}$ and Nattie, Neuroscience, 2012), and (2) significantly decreased ABP in both resting and hypercapnic condition (Li et al., 2013a) (Li and Nattie, Neuroscience, 2012). We hypothesize that the source of the enhanced SNA and respiratory-sympathetic coupling may involve neurons in the central chemoreceptor sites, and the overactive central orexin system may play an important role in such an alteration. There is no evidence that orexin projections and orexin receptors are located in the peripheral chemoreceptors, e.g., the carotid body, at the present time and the role of peripheral orexins in regulation of cardio-respiratory functions remain unclear (Johren et al., 2001; Nakabayashi et al., 2003; Heinonen et al., 2008).

In summary: transgenic orexin deficient mice and rats have lower resting blood pressure, and a significantly decreased hypercapnic response (pp-OX KO) while SHRs have severe hypertension, a hyperactive central hypercapnic reflex, and possibly an overactive orexin system. Blocking both orexin receptors in SHR can normalize the exaggerated hypercapnic chemoreflex and significantly lower blood pressure, which suggests the overactive central chemoreceptors may be an important link in neurogenic hypertension with orexin as mediator in SHRs.

\section{SUMMARY OF OREXIN, CHEMOREFLEX, AND HYPERTENSION}

Orexin knockout mice have both a severely attenuated hypercapnic chemoreflex and lower resting blood pressure, while SHRs have severely increased blood pressure and enhanced peripheral and central chemoreflexes with a possibly upregulated central orexin system. Antagonism of both orexin receptors can significantly lower SNA and blood pressure and normalize that central hypercapnic chemoreflex in SHRs. We suggest that overactive central chemoreceptors may be an important link to the development and maintenance of high blood pressure in SHRs with orexin as a key mediator.

\section{CONCLUSION}

Activation of central $\mathrm{CO}_{2}$ chemoreceptors is associated with sympatho-excitation, hypertension and tachycardia. In SHRs, the overactive central and peripheral chemoreflex may play an important role in the development of neurogenic hypertension. Orexin links the respiratory and sympathetic nervous systems and an overactive orexin system may be the cause of hyperactive central $\mathrm{CO}_{2}$ chemoreflex in SHRs and thus the associated hypertension. Antagonism of OXRs can normalize the overactive $\mathrm{CO}_{2}$ central chemoreflex and significantly lower ABP and SNA in SHRs. Based on the data obtained from SHRs we hypothesize that modulation of the orexin system could be a potential target in treating some forms of hypertension.

\section{REFERENCES}

Abdala, A. P., Mcbryde, F. D., Marina, N., Hendy, E. B., Engelman, Z., Fudim, M., et al. (2012). Hypertension is critically dependent on the carotid body input in the spontaneously hypertensive rat. J. Physiol. 590, 4269-4277. doi: 10.1113/jphysiol.2012.237800

Allen, G. V., and Cechetto, D. F. (1992). Functional and anatomical organization of cardiovascular pressor and depressor sites in the lateral hypothalamic area: I. Descending projections. J. Comp. Neurol. 315, 313-332. doi: $10.1002 /$ cne. 903150307

Antunes, V. R., Brailoiu, G. C., Kwok, E. H., Scruggs, P., and Dun, N. J. (2001). Orexins/hypocretins excite rat sympathetic preganglionic neurons in vivo and in vitro. Am. J. Physiol. Regul. Integr. Comp. Physiol. 281, R1801-R1807.

Badami, V. M., Rice, C. D., Lois, J. H., Madrecha, J., and Yates, B. J. (2010) Distribution of hypothalamic neurons with orexin (hypocretin) or melanin concentrating hormone $(\mathrm{MCH})$ immunoreactivity and multisynaptic connections with diaphragm motoneurons. Brain Res. 1323, 119-126. doi: 10.1016/j.brainres.2010.02.002

Bayer, L., Eggermann, E., Serafin, M., Grivel, J., Machard, D., Muhlethaler, M., et al. (2005). Opposite effects of noradrenaline and acetylcholine upon hypocretin/orexin versus melanin concentrating hormone neurons in rat hypothalamic slices. Neuroscience 130, 807-811. doi: 10.1016/j.neuroscience.2004.10.032

Boone, J. L. (1991). Stress and hypertension. Prim. Care 18, 623-649.

Brown, S. N., Chitravanshi, V. C., Kawabe, K., and Sapru, H. N. (2007). Microinjections of melanin concentrating hormone into the nucleus tractus solitarius of the rat elicit depressor and bradycardic responses. Neuroscience 150, 796-806. doi: 10.1016/j.neuroscience.2007.10.002

Burdakov, D., Karnani, M. M., and Gonzalez, A. (2013). Lateral hypothalamus as a sensor-regulator in respiratory and metabolic control. Physiol. Behav. 121, 117-124. doi: 10.1016/j.physbeh.2013.03.023

Chau, E. H., Lam, D., Wong, J., Mokhlesi, B., and Chung, F. (2012). Obesity hypoventilation syndrome: a review of epidemiology, pathophysiology, and perioperative considerations. Anesthesiology 117, 188-205. doi: 10.1097/ALN.0b013e31825add60

Chen, C. T., Hwang, L. L., Chang, J. K., and Dun, N. J. (2000). Pressor effects of orexins injected intracisternally and to rostral ventrolateral medulla of anesthetized rats. Am. J. Physiol. Regul. Integr. Comp. Physiol. 278, R692-R697.

Cooper, V. L., Bowker, C. M., Pearson, S. B., Elliott, M. W., and Hainsworth, R. (2004). Effects of simulated obstructive sleep apnoea on the human carotid baroreceptor-vascular resistance reflex. J. Physiol. 557, 1055-1065. doi: 10.1113/jphysiol.2004.062513

Cooper, V. L., Pearson, S. B., Bowker, C. M., Elliott, M. W., and Hainsworth, R. (2005). Interaction of chemoreceptor and baroreceptor reflexes by hypoxia and hypercapnia - a mechanism for promoting hypertension in obstructive sleep apnoea. J. Physiol. 568, 677-687. doi: 10.1113/jphysiol.2005.094151 
Costa-Silva, J. H., Zoccal, D. B., and Machado, B. H. (2012). Chronic intermittent hypoxia alters glutamatergic control of sympathetic and respiratory activities in the commissural NTS of rats. Am. J. Physiol. Regul. Integr. Comp. Physiol. 302, R785-R793. doi: 10.1152/ajpregu.00363.2011

Czyzyk-Krzeska, M. F., and Trzebski, A. (1990). Respiratory-related discharge pattern of sympathetic nerve activity in the spontaneously hypertensive rat. J. Physiol. 426, 355-368.

Date, Y., Ueta, Y., Yamashita, H., Yamaguchi, H., Matsukura, S., Kangawa, K., et al. (1999). Orexins, orexigenic hypothalamic peptides, interact with autonomic, neuroendocrine and neuroregulatory systems. Proc. Natl. Acad. Sci. U.S.A. 96, 748-753.

De Lecea, L. (2010). A decade of hypocretins: past, present and future of the neurobiology of arousal. Acta Physiol. 198, 203-208. doi: 10.1111/j.17481716.2009.02004.x

De Lecea, L. (2012). Hypocretins and the neurobiology of sleep-wake mechanisms. Prog. Brain Res. 198, 15-24. doi: 10.1016/B978-0-444-59489-1.00003-3

De Lecea, L., Kilduff, T. S., Peyron, C., Gao, X., Foye, P. E., Danielson, P. E., et al. (1998). The hypocretins: hypothalamus-specific peptides with neuroexcitatory activity. Proc. Natl. Acad. Sci. U.S.A. 95, 322-327. doi: 10.1073/pnas.95.1.322

Deng, B. S., Nakamura, A., Zhang, W., Yanagisawa, M., Fukuda, Y., and Kuwaki, T. (2007). Contribution of orexin in hypercapnic chemoreflex: evidence from genetic and pharmacological disruption and supplementation studies in mice. J. Appl. Physiol. (1985) 103, 1772-1779. doi: 10.1152/japplphysiol.00075.2007

Dias, M. B., Li, A., and Nattie, E. (2010). The orexin receptor 1 (OX1R) in the rostral medullary raphe contributes to the hypercapnic chemoreflex in wakefulness, during the active period of the diurnal cycle. Respir. Physiol. Neurobiol. 170, 96-102. doi: 10.1016/j.resp.2009.12.002

Dias, M. B., Li, A., and Nattie, E. E. (2009). Antagonism of orexin receptor-1 in the retrotrapezoid nucleus inhibits the ventilatory response to hypercapnia predominantly in wakefulness. J. Physiol. 587, 2059-2067. doi: 10.1113/jphysiol.2008.168260

Dutschmann, M., Kron, M., Morschel, M., and Gestreau, C. (2007). Activation of Orexin B receptors in the pontine Kolliker-Fuse nucleus modulates preinspiratory hypoglossal motor activity in rat. Respir. Physiol. Neurobiol. 159, 232-235. doi: 10.1016/j.resp.2007.06.004

Fisher, J. P., and Paton, J. F. (2011). The sympathetic nervous system and blood pressure in humans: implications for hypertension. J. Hum. Hypertens. 26, 463-475. doi: $10.1038 /$ ihh.2011.66

Fletcher, E. C. (2001). Invited review: physiological consequences of intermittent hypoxia: systemic blood pressure. J. Appl. Physiol. (1985) 90, 1600-1605.

Fletcher, E. C., Lesske, J., Behm, R., Miller, C. C. 3rd., Stauss, H., and Unger, T. (1992). Carotid chemoreceptors, systemic blood pressure, and chronic episodic hypoxia mimicking sleep apnea. J. Appl. Physiol. (1985) 72, 1978-1984.

Follwell, M. J., and Ferguson, A. V. (2002). Cellular mechanisms of orexin actions on paraventricular nucleus neurones in rat hypothalamus. J. Physiol. 545, 855-867. doi: 10.1113/jphysiol.2002.030049

Fukuda, Y., Sato, A., and Trzebski, A. (1987). Carotid chemoreceptor discharge responses to hypoxia and hypercapnia in normotensive and spontaneously hypertensive rats. J. Auton. Nerv. Syst. 19, 1-11. doi: 10.1016/01651838(87)90139-1

Furlong, T. M., Vianna, D. M., Liu, L., and Carrive, P. (2009). Hypocretin/orexin contributes to the expression of some but not all forms of stress and arousal. Eur. J. Neurosci. 30, 1603-1614. doi: 10.1111/j.1460-9568.2009.06952.x

Geerling, J. C., Shin, J. W., Chimenti, P. C., and Loewy, A. D. (2010). Paraventricular hypothalamic nucleus: axonal projections to the brainstem. J. Comp. Neurol. 518, 1460-1499. doi: 10.1002/cne.22283

Girault, E. M., Yi, C. X., Fliers, E., and Kalsbeek, A. (2012). Orexins, feeding, and energy balance. Prog. Brain Res. 198, 47-64. doi: 10.1016/B978-0-444-594891.00005-7

Guyenet, P. G. (2006). The sympathetic control of blood pressure. Nat. Rev Neurosci. 7, 335-346. doi: 10.1038/nrn1902

Guyenet, P. G., Stornetta, R. L., Abbott, S. B., Depuy, S. D., Fortuna, M. G., and Kanbar, R. (2010). Central CO2 chemoreception and integrated neural mechanisms of cardiovascular and respiratory control. J. Appl. Physiol. 108, 995-1002. doi: 10.1152/japplphysiol.00712.2009

Hall, J. E., Da Silva, A. A., Do Carmo, J. M., Dubinion, J., Hamza, S., Munusamy, S., et al. (2010). Obesity-induced hypertension: role of sympathetic nervous system, leptin, and melanocortins. J. Biol. Chem. 285, 17271-17276. doi: 10.1074/jbc.R110.113175
Hanna, B. D., Lioy, F., and Polosa, C. (1981). Role of carotid and central chemoreceptors in the $\mathrm{CO} 2$ response of sympathetic preganglionic neurons. J. Auton Nerv. Syst. 3, 421-435.

Hassani, O. K., Lee, M. G., and Jones, B. E. (2009). Melanin-concentrating hormone neurons discharge in a reciprocal manner to orexin neurons across the sleep-wake cycle. Proc. Natl. Acad. Sci. U.S.A. 106, 2418-2422. doi: 10.1073/pnas.0811400106

Heinonen, M. V., Purhonen, A. K., Makela, K. A., and Herzig, K. H. (2008). Functions of orexins in peripheral tissues. Acta Physiol. 192, 471-485. doi: 10.1111/j.1748-1716.2008.01836.x

Huang, S. C., Dai, Y. W., Lee, Y. H., Chiou, L. C., and Hwang, L. L. (2010). Orexins depolarize rostral ventrolateral medulla neurons and increase arterial pressure and heart rate in rats mainly via orexin 2 receptors. J. Pharmacol. Exp. Ther. 334, 522-529. doi: 10.1124/jpet.110.167791

Iigaya, K., Horiuchi, J., Mcdowall, L. M., Lam, A. C., Sediqi, Y., Polson, J. W., et al. (2012). Blockade of orexin receptors with Almorexant reduces cardiorespiratory responses evoked from the hypothalamus but not baro- or chemoreceptor reflex responses. Am. J. Physiol. Regul. Integr. Comp. Physiol. 303, R1011-R1022. doi: 10.1152/ajpregu.00263.2012

Izdebska, E., Jodkowski, J., and Trzebski, A. (1982). Central influence of vasopressin on baroreceptor reflex in normotensive rats and its lack in spontaneously hypertensive rats (SHR). Experientia 38, 594-595.

Jansen, A. S., Wessendorf, M. W., and Loewy, A. D. (1995). Transneuronal labeling of CNS neuropeptide and monoamine neurons after pseudorabies virus injections into the stellate ganglion. Brain Res, 683, 1-24. doi: 10.1016/00068993(95)00276-V

Johnson, P. L., Molosh, A., Fitz, S. D., Truitt, W. A., and Shekhar, A. (2012). Orexin, stress, and anxiety/panic states. Prog. Brain Res. 198, 133-161. doi: 10.1016/B978-0-444-59489-1.00009-4

Johnson, P. L., Truitt, W., Fitz, S. D., Minick, P. E., Dietrich, A., Sanghani, S., et al. (2010). A key role for orexin in panic anxiety. Nat. Med. 16, 111-115. doi: $10.1038 / \mathrm{nm} .2075$

Johren, O., Bruggemann, N., and Dominiak, P. (2004). Orexins (hypocretins) and adrenal function. Horm. Metab Res. 36, 370-375. doi: 10.1055/s-2004-814569

Johren, O., Neidert, S. J., Kummer, M., Dendorfer, A., and Dominiak, P. (2001). Prepro-orexin and orexin receptor mRNAs are differentially expressed in peripheral tissues of male and female rats. Endocrinology 142, 3324-3331. doi: 10.1210/en.142.8.3324

Kara, T., Narkiewicz, K., and Somers, V. K. (2003). Chemoreflexes-physiology and clinical implications. Acta Physiol. Scand 177, 377-384. doi: 10.1046/j.1365201X.2003.01083.x

Karnani, M. M., Szabo, G., Erdelyi, F., and Burdakov, D. (2013). Lateral hypothalamic GAD65 neurons are spontaneously firing and distinct from orexinand melanin-concentrating hormone neurons. J. Physiol. 591, 933-953. doi: 10.1113/jphysiol.2012.243493

Kayaba, Y., Nakamura, A., Kasuya, Y., Ohuchi, T., Yanagisawa, M., Komuro, I., et al. (2003). Attenuated defense response and low basal blood pressure in orexin knockout mice. Am. J. Physiol. Regul. Integr. Comp. Physiol. 285, R581-R593. doi: 10.1152/ajpregu.00671.2002

Kirchgessner, A. L., and Liu, M. (1999). Orexin synthesis and response in the gut. Neuron 24, 941-951.

Konadhode, R. R., Pelluru, D., Blanco-Centurion, C., Zayachkivsky, A., Liu, M., Uhde, T., et al. (2013). Optogenetic stimulation of MCH neurons increases sleep. J. Neurosci. 33, 10257-10263. doi: 10.1523/JNEUROSCI.1225-13.2013

Kukkonen, J. P. (2013). Physiology of the orexinergic/hypocretinergic system: a revisit in 2012. Am. J. Physiol. Cell Physiol. 304, C2-C32. doi: 10.1152/ajpcell.00227.2012

Kukkonen, J. P., Holmqvist, T., Ammoun, S., and Akerman, K. E. (2002). Functions of the orexinergic/hypocretinergic system. Am. J. Physiol. Cell Physiol. 283, C1567-C1591. doi: 10.1152/ajpcell.00055.2002

Kuwaki, T., Zhang, W., Nakamura, A., and Deng, B. S. (2008). Emotional and state-dependent modification of cardiorespiratory function: role of orexinergic neurons. Auton. Neurosci. 142, 11-16. doi: 10.1016/j.autneu.2008.03.004

Lazarenko, R. M., Stornetta, R. L., Bayliss, D. A., and Guyenet, P. G. (2011). Orexin A activates retrotrapezoid neurons in mice. Respir Physiol. Neurobiol. 175, 283-287. doi: 10.1016/j.resp.2010.12.003

Lee, Y. H., Dai, Y. W., Huang, S. C., Li, T. L., and Hwang, L. L. (2013). Blockade of central orexin 2 receptors reduces arterial pressure in spontaneously hypertensive rats. Exp. Physiol. 98, 1145-1155. doi: 10.1113/expphysiol.2013.072298 
Leinninger, G. M. (2011). Lateral thinking about leptin: a review of leptin action via the lateral hypothalamus. Physiol. Behav. 104, 572-581. doi: 10.1016/j.physbeh.2011.04.060

Leinninger, G. M., and Myers, M. G. Jr. (2008). LRb signals act within a distributed network of leptin-responsive neurones to mediate leptin action. Acta Physiol. 192, 49-59. doi: 10.1111/j.1748-1716.2007.01784.x

Leonard, C. S., and Kukkonen, J. P. (2013). Orexin/hypocretin receptor signalling: a functional perspective. Br. J. Pharmacol. 171, 294-313. doi: 10.1111/bph.12296

Lesske, J., Fletcher, E. C., Bao, G., and Unger, T. (1997). Hypertension caused by chronic intermittent hypoxia-influence of chemoreceptors and sympathetic nervous system. J. Hypertens 15, 1593-1603. doi: 10.1097/00004872-19971512000060

Li, A., Hindmarch, C. C., Nattie, E. E., and Paton, J. F. (2013a). Antagonism of orexin receptors significantly lowers blood pressure in spontaneously hypertensive rats. J. Physiol. 591, 4237-4248. doi: 10.1113/jphysiol.2013.256271

Li, A., Hindmarch, C. C., Nattie, E. E., and Paton, J. F. (2013b). Reply from aihua li, charles C. T. Hindmarch, eugene e. Nattie and julian f. R. Paton. J. Physiol. 591, 6117. doi: 10.1113/jphysiol.2013.266064

Li, A., and Nattie, E. (2010). Antagonism of rat orexin receptors by almorexant attenuates central chemoreception in wakefulness in the active period of the diurnal cycle. J. Physiol. 588, 2935-2944. doi: 10.1113/jphysiol.2010.191288

Li, A., and Nattie, E. E. (2012). "Antagonism of orexin receptors reduces the exaggerated respiratory response to hypercapnia observed in conscious spontaneous hypertensive rats," in Neuroscience Meeting Planner (New Orleans, LA: Society for Neuroscience).

Lioy, F., and Trzebski, A. (1984). Pressor effect of CO2 in the rat: different thresholds of the central cardiovascular and respiratory responses to $\mathrm{CO} 2$. J. Auton. Nerv. Syst. 10, 43-54.

Lopez, M., Senaris, R., Gallego, R., Garcia-Caballero, T., Lago, F., Seoane, L., et al. (1999). Orexin receptors are expressed in the adrenal medulla of the rat. Endocrinology 140, 5991-5994.

Louis, G. W., Leinninger, G. M., Rhodes, C. J., and Myers, M. G. Jr. (2010). Direct innervation and modulation of orexin neurons by lateral hypothalamic LepRb neurons. J. Neurosci. 30, 11278-11287. doi: 10.1523/JNEUROSCI.1340-10.2010

Luong, L. N., and Carrive, P. (2012). Orexin microinjection in the medullary raphe increases heart rate and arterial pressure but does not reduce tail skin blood flow in the awake rat. Neuroscience 202, 209-217. doi: 10.1016/j.neuroscience.2011.11.073

Machado, B. H., Bonagamba, L. G., Dun, S. L., Kwok, E. H., and Dun, N. J. (2002). Pressor response to microinjection of orexin/hypocretin into rostral ventrolateral medulla of awake rats. Regul. Pept. 104, 75-81. doi: 10.1016/S01670115(01)00351-2

Marcus, J. N., Aschkenasi, C. J., Lee, C. E., Chemelli, R. M., Saper, C. B., Yanagisawa, M., et al. (2001). Differential expression of orexin receptors 1 and 2 in the rat brain. J. Comp. Neurol. 435, 6-25. doi: 10.1002/cne.1190

Markovitz, J. H., Matthews, K. A., Kannel, W. B., Cobb, J. L., and D'agostino, R. B. (1993). Psychological predictors of hypertension in the Framingham Study. Is there tension in hypertension? JAMA 270, 2439-2443. doi: 10.1001/jama.1993.03510200045030

Marques, F. Z., Campain, A. E., Davern, P. J., Yang, Y. H., Head, G. A., and Morris, B. J. (2011a). Genes influencing circadian differences in blood pressure in hypertensive mice. PLOS ONE 6:e19203. doi: 10.1371/journal.pone.0019203

Marques, F. Z., Campain, A. E., Davern, P. J., Yang, Y. H., Head, G. A., and Morris, B. J. (2011b). Global identification of the genes and pathways differentially expressed in hypothalamus in early and established neurogenic hypertension. Physiol. Genomics 43, 766-771. doi: 10.1152/physiolgenomics. 00009.2011

Matsumura, K., Tsuchihashi, T., and Abe, I. (2001). Central orexin-A augments sympathoadrenal outflow in conscious rabbits. Hypertension 37, 1382-1387. doi: 10.1161/01.HYP.37.6.1382

Messina, M. M., and Overton, J. M. (2007). Cardiovascular effects of melanin-concentrating hormone. Regul. Pept. 139, 23-30. doi: 10.1016/j.regpep.2006.08.013

Monti, J. M., Torterolo, P., and Lagos, P. (2013). Melanin-concentrating hormone control of sleep-wake behavior. Sleep Med. Rev. 17, 293-298. doi: 10.1016/j.smrv.2012.10.002

Moraes, D. J., Zoccal, D. B., and Machado, B. H. (2012a). Medullary respiratory network drives sympathetic overactivity and hypertension in rats submitted to chronic intermittent hypoxia. Hypertension 60, 1374-1380. doi: 10.1161/HYPERTENSIONAHA.111.189332

Moraes, D. J., Zoccal, D. B., and Machado, B. H. (2012b). Sympathoexcitation during chemoreflex active expiration is mediated by L-glutamate in the RVLM/Botzinger complex of rats. J. Neurophysiol. 108, 610-623. doi: 10.1152/jn.00057.2012

Moreira, T. S., Takakura, A. C., Colombari, E., and Guyenet, P. G. (2006). Central chemoreceptors and sympathetic vasomotor outflow. J. Physiol. 577, 369-386. doi: 10.1113/jphysiol.2006.115600

Morgan, B. J., Crabtree, D. C., Palta, M., and Skatrud, J. B. (1995). Combined hypoxia and hypercapnia evokes long-lasting sympathetic activation in humans. J. Appl. Physiol. (1985) 79, 205-213.

Muraki, Y., Yamanaka, A., Tsujino, N., Kilduff, T. S., Goto, K., and Sakurai, T (2004). Serotonergic regulation of the orexin/hypocretin neurons through the 5-HT1A receptor. J. Neurosci. 24, 7159-7166. doi: 10.1523/JNEUROSCI.102704.2004

Nahon, J. L. (2006). The melanocortins and melanin-concentrating hormone in the central regulation of feeding behavior and energy homeostasis. $C R$ Biol. 329, 623-638; discussion: 653-625. doi: 10.1016/j.crvi.2006.03.021

Nakabayashi, M., Suzuki, T., Takahashi, K., Totsune, K., Muramatsu, Y., Kaneko, C., et al. (2003). Orexin-A expression in human peripheral tissues. Mol. Cell Endocrinol. 205, 43-50. doi: 10.1016/S0303-7207(03)00206-5

Nakamura, A., Zhang, W., Yanagisawa, M., Fukuda, Y., and Kuwaki, T. (2007) Vigilance state-dependent attenuation of hypercapnic chemoreflex and exaggerated sleep apnea in orexin knockout mice. J. Appl. Physiol. 102, 241-248. doi: 10.1152/japplphysiol.00679.2006

Nambu, T., Sakurai, T., Mizukami, K., Hosoya, Y., Yanagisawa, M., and Goto, K. (1999). Distribution of orexin neurons in the adult rat brain. Brain Res. 827, 243-260. doi: 10.1016/S0006-8993(99)01336-0

Nattie, E., and Li, A. (2012). Respiration and autonomic regulation and orexin. Prog. Brain Res. 198, 25-46. doi: 10.1016/B978-0-444-59489-1.00004-5

Nattie, E. E., Blanchford, C., and Li, A. (1992). Retrofacial lesions: effects on CO2sensitive phrenic and sympathetic nerve activity. J. Appl. Physiol. 73, 1317-1325.

Nattie, E. E., Gdovin, M., and Li, A. (1993). Retrotrapezoid nucleus glutamate receptors: control of CO2-sensitive phrenic and sympathetic output. J. Appl. Physiol. 74, 2958-2968.

Nixon, J. P., Kotz, C. M., Novak, C. M., Billington, C. J., and Teske, J. A. (2012). Neuropeptides controlling energy balance: orexins and neuromedins. Handb. Exp. Pharmacol. 209, 77-109. doi: 10.1007/978-3-642-24716-3_4

Oikawa, S., Hirakawa, H., Kusakabe, T., Nakashima, Y., and Hayashida, Y. (2005) Autonomic cardiovascular responses to hypercapnia in conscious rats: the roles of the chemo- and baroreceptors. Auton. Neurosci. 117, 105-114. doi: 10.1016/j.autneu.2004.11.009

Ouedraogo, R., Naslund, E., and Kirchgessner, A. L. (2003). Glucose regulates the release of orexin-a from the endocrine pancreas. Diabetes 52, 111-117. doi: 10.2337/diabetes.52.1.111

Paton, J. F., Sobotka, P. A., Fudim, M., Engleman, Z. J., Hart, E. C., Mcbryde, F. D., et al. (2013). The carotid body as a therapeutic target for the treatment of sympathetically mediated diseases. Hypertension 61, 5-13. doi: 10.1161/HYPERTENSIONAHA.111.00064

Peever, J. H., Lai, Y. Y., and Siegel, J. M. (2003). Excitatory effects of hypocretin-1 (orexin-A) in the trigeminal motor nucleus are reversed by NMDA antagonism. J. Neurophysiol. 89, 2591-2600. doi: 10.1152/jn.00968.2002

Peyron, C., Sapin, E., Leger, L., Luppi, P. H., and Fort, P. (2009). Role of the melanin-concentrating hormone neuropeptide in sleep regulation. Peptides 30, 2052-2059. doi: 10.1016/j.peptides.2009.07.022

Peyron, C., Tighe, D. K., Van Den Pol, A. N., De Lecea, L., Heller, H. C., Sutcliffe, J. G., et al. (1998). Neurons containing hypocretin (orexin) project to multiple neuronal systems. J. Neurosci. 18, 9996-10015.

Prabhakar, N. R., Fields, R. D., Baker, T., and Fletcher, E. C. (2001). Intermittent hypoxia: cell to system. Am. J. Physiol. Lung. Cell. Mol. Physiol. 281, L524-L528

Prabhakar, N. R., Kumar, G. K., and Peng, Y. J. (2012). Sympatho-adrenal activation by chronic intermittent hypoxia. J. Appl. Physiol. (1985) 113, 1304-1310. doi: 10.1152/japplphysiol.00444.2012

Prabhakar, N. R., Peng, Y. J., Jacono, F. J., Kumar, G. K., and Dick, T. E. (2005). Cardiovascular alterations by chronic intermittent hypoxia: importance of carotid body chemoreflexes. Clin. Exp. Pharmacol. Physiol. 32, 447-449. doi: 10.1111/j.1440-1681.2005.04209.x 
Puskas, N., Papp, R. S., Gallatz, K., and Palkovits, M. (2010). Interactions between orexin-immunoreactive fibers and adrenaline or noradrenaline-expressing neurons of the lower brainstem in rats and mice. Peptides 31, 1589-1597. doi: 10.1016/j.peptides.2010.04.020

Rosin, D. L., Chang, D. A., and Guyenet, P. G. (2006). Afferent and efferent connections of the rat retrotrapezoid nucleus. J. Comp. Neurol. 499, 64-89. doi: $10.1002 / \mathrm{cne} .21105$

Sakurai, T. (2007). The neural circuit of orexin (hypocretin): maintaining sleep and wakefulness. Nat. Rev. Neurosci. 8, 171-181. doi: 10.1038/nrn2092

Sakurai, T., Amemiya, A., Ishii, M., Matsuzaki, I., Chemelli, R. M., Tanaka, H., et al. (1998). Orexins and orexin receptors: a family of hypothalamic neuropeptides and $\mathrm{G}$ protein-coupled receptors that regulate feeding behavior. Cell 92 , 573-585. doi: 10.1016/S0092-8674(00)80949-6

Sakurai, T., Mieda, M., and Tsujino, N. (2010). The orexin system: roles in sleep/wake regulation. Ann. N.Y. Acad. Sci. 1200, 149-161. doi: 10.1111/j.17496632.2010.05513.x

Samson, W. K., Bagley, S. L., Ferguson, A. V., and White, M. M. (2007). Hypocretin/orexin type 1 receptor in brain: role in cardiovascular control and the neuroendocrine response to immobilization stress. Am. J. Physiol. Regul. Integr. Comp. Physiol. 292, R382-R387. doi: 10.1152/ajpregu.00496.2006

Samson, W. K., Gosnell, B., Chang, J. K., Resch, Z. T., and Murphy, T. C. (1999). Cardiovascular regulatory actions of the hypocretins in brain. Brain Res. 831, 248-253. doi: 10.1016/S0006-8993(99)01457-2

Schone, C., Cao, Z. F., Apergis-Schoute, J., Adamantidis, A., Sakurai, T., and Burdakov, D. (2012). Optogenetic probing of fast glutamatergic transmission from hypocretin/orexin to histamine neurons in situ. J. Neurosci. 32, 12437-12443. doi: 10.1523/JNEUROSCI.0706-12.2012

Schone, C., Venner, A., Knowles, D., Karnani, M. M., and Burdakov, D. (2011). Dichotomous cellular properties of mouse orexin/hypocretin neurons. J. Physiol. 589, 2767-2779. doi: 10.1113/jphysiol.2011.208637

Schultz, H. D., Li, Y. L., and Ding, Y. (2007). Arterial chemoreceptors and sympathetic nerve activity: implications for hypertension and heart failure. Hypertension 50, 6-13. doi: 10.1161/HYPERTENSIONAHA.106.076083

Schwimmer, H., Stauss, H. M., Abboud, F., Nishino, S., Mignot, E., and Zeitzer, J. M. (2010). Effects of sleep on the cardiovascular and thermoregulatory systems: a possible role for hypocretins. J. Appl. Physiol. 109, 1053-1063. doi: 10.1152/japplphysiol.00516.2010

Shahid, I. Z., Rahman, A. A., and Pilowsky, P. M. (2011). Intrathecal orexin A increases sympathetic outflow and respiratory drive, enhances baroreflex sensitivity and blocks the somato-sympathetic reflex. Br. J. Pharmacol. 162, 961-973. doi: 10.1111/j.1476-5381.2010.01102.x

Shahid, I. Z., Rahman, A. A., and Pilowsky, P. M. (2012). Orexin A in rat rostral ventrolateral medulla is pressor, sympatho-excitatory, increases barosensitivity and attenuates the somato-sympathetic reflex. Br. J. Pharmacol. 165, 2292-2303. doi: 10.1111/j.1476-5381.2011.01694.x

Shirasaka, T., Kunitake, T., Takasaki, M., and Kannan, H. (2002). Neuronal effects of orexins: relevant to sympathetic and cardiovascular functions. Regul. Pept. 104, 91-95. doi: 10.1016/S0167-0115(01)00352-4

Shirasaka, T., Miyahara, S., Kunitake, T., Jin, Q. H., Kato, K., Takasaki, M., et al. (2001). Orexin depolarizes rat hypothalamic paraventricular nucleus neurons. Am. J. Physiol. Regul. Integr. Comp. Physiol. 281, R1114-R1118.

Shirasaka, T., Nakazato, M., Matsukura, S., Takasaki, M., and Kannan, H. (1999). Sympathetic and cardiovascular actions of orexins in conscious rats. Am. J. Physiol. 277, R1780-R1785.

Simms, A. E., Paton, J. F., Allen, A. M., and Pickering, A. E. (2010). Is augmented central respiratory-sympathetic coupling involved in the generation of hypertension? Respir Physiol. Neurobiol. 174, 89-97. doi: 10.1016/j.resp.2010.07.010.

Simms, A. E., Paton, J. F., Pickering, A. E., and Allen, A. M. (2009). Amplified respiratory-sympathetic coupling in the spontaneously hypertensive rat: does it contribute to hypertension? J. Physiol. 587, 597-610. doi: 10.1113/jphysiol.2008.165902

Sinski, M., Lewandowski, J., Przybylski, J., Bidiuk, J., Abramczyk, P., Ciarka, A., et al. (2012). Tonic activity of carotid body chemoreceptors contributes to the increased sympathetic drive in essential hypertension. Hypertens. Res. 35 , 487-491. doi: 10.1038/hr.2011.209

Smith, T. L., and Hutchins, P. M. (1979). Central hemodynamics in the developmental stage of spontaneous hypertension in the unanesthetized rat Hypertension 1, 508-517.
Somers, V. K., Mark, A. L., and Abboud, F. M. (1988a). Potentiation of sympathetic nerve responses to hypoxia in borderline hypertensive subjects. Hypertension 11, 608-612.

Somers, V. K., Mark, A. L., and Abboud, F. M. (1988b). Sympathetic activation by hypoxia and hypercapnia-implications for sleep apnea. Clin. Exp. Hypertens A 10(Suppl. 1), 413-422.

Somers, V. K., Mark, A. L., Zavala, D. C., and Abboud, F. M. (1989). Contrasting effects of hypoxia and hypercapnia on ventilation and sympathetic activity in humans. J. Appl. Physiol. 67, 2101-2106.

Song, N., Zhang, G., Geng, W., Liu, Z., Jin, W., Li, L., et al. (2012). Acid sensing ion channel 1 in lateral hypothalamus contributes to breathing control. PLoS ONE 7:e39982. doi: 10.1371/journal.pone.0039982

Spinazzi, R., Andreis, P. G., Rossi, G. P., and Nussdorfer, G. G. (2006). Orexins in the regulation of the hypothalamic-pituitary-adrenal axis. Pharmacol. Rev. 58, 46-57. doi: 10.1124/pr.58.1.4.

Sun, M. K., and Guyenet, P. G. (1986). Hypothalamic glutamatergic input to medullary sympathoexcitatory neurons in rats. Am. J. Physiol. 251, R798-R810.

Tafil-Klawe, M., Trzebski, A., and Klawe, J. (1985a). Contribution of the carotid chemoreceptor reflex to the mechanism of respiratory sinus arrhythmia in young healthy and hypertensive humans. Acta Physiol. Pol. 36, 59-64.

Tafil-Klawe, M., Trzebski, A., Klawe, J., and Palko, T. (1985b). Augmented chemoreceptor reflex tonic drive in early human hypertension and in normotensive subjects with family background of hypertension. Acta Physiol. Pol. 36, 51-58.

Takakusaki, K., Takahashi, K., Saitoh, K., Harada, H., Okumura, T., Kayama, Y., et al. (2005). Orexinergic projections to the cat midbrain mediate alternation of emotional behavioural states from locomotion to cataplexy. J. Physiol. 568, 1003-1020. doi: 10.1113/jphysiol.2005.085829

Tan, Z. Y., Lu, Y., Whiteis, C. A., Simms, A. E., Paton, J. F., Chapleau, M. W., et al. (2010). Chemoreceptor hypersensitivity, sympathetic excitation, and overexpression of ASIC and TASK channels before the onset of hypertension in SHR. Circ. Res. 106, 536-545. doi: 10.1161/CIRCRESAHA.109.206946

Teske, J. A., Billington, C. J., and Kotz, C. M. (2010). Hypocretin/orexin and energy expenditure. Acta Physiol. 198, 303-312. doi: 10.1111/j.1748-1716.2010.02075.x

Thorpe, A. J., and Kotz, C. M. (2005). Orexin A in the nucleus accumbens stimulates feeding and locomotor activity. Brain Res. 1050, 156-162. doi: 10.1016/j.brainres.2005.05.045

Trivedi, P., Yu, H., Macneil, D. J., Van Der Ploeg, L. H., and Guan, X. M. (1998). Distribution of orexin receptor mRNA in the rat brain. FEBS Lett. 438, 71-75.

Trzebski, A., Tafil, M., Zoltowski, M., and Przybylski, J. (1982). Increased sensitivity of the arterial chemoreceptor drive in young men with mild hypertension. Cardiovasc. Res. 16, 163-172.

Tsujino, N., and Sakurai, T. (2009). Orexin/hypocretin: a neuropeptide at the interface of sleep, energy homeostasis, and reward system. Pharmacol Rev. 61, 162-176. doi: 10.1124/pr.109.001321

Tupone, D., Madden, C. J., Cano, G., and Morrison, S. F. (2011). An orexinergic projection from perifornical hypothalamus to raphe pallidus increases rat brown adipose tissue thermogenesis. J. Neurosci. 31, 15944-15955. doi: 10.1523/JNEUROSCI.3909-11.2011

Williams, R. H., Jensen, L. T., Verkhratsky, A., Fugger, L., and Burdakov, D. (2007) Control of hypothalamic orexin neurons by acid and CO2. Proc. Natl. Acad. Sci. U.S.A. 104, 10685-10690. doi: 10.1073/pnas.0702676104

Xiao, F., Jiang, M., Du, D., Xia, C., Wang, J., Cao, Y., et al. (2013). Orexin A regulates cardiovascular responses in stress-induced hypertensive rats. Neuropharmacology 67, 16-24. doi: 10.1016/j.neuropharm.2012.10.021

Yamada, K., Asanoi, H., Ueno, H., Joho, S., Takagawa, J., Kameyama, T., et al. (2004). Role of central sympathoexcitation in enhanced hypercapnic chemosensitivity in patients with heart failure. Am. Heart J. 148, 964-970. doi: 10.1016/j.ahj.2004.05.030

Yamamoto, H., Okuzaki, D., Yamanishi, K., Xu, Y., Watanabe, Y., Yoshida, M., et al. (2013). Genetic analysis of genes causing hypertension and stroke in spontaneously hypertensive rats. Int. J. Mol. Med. 31, 1057-1065. doi: 10.3892/ijmm.2013.1304

Yamanaka, A., Muraki, Y., Ichiki, K., Tsujino, N., Kilduff, T. S., Goto, K., et al. (2006). Orexin neurons are directly and indirectly regulated by catecholamines in a complex manner. J. Neurophysiol. 96, 284-298. doi: 10.1152/jn.01361.2005

Young, J. K., Wu, M., Manaye, K. F., Kc, P., Allard, J. S., Mack, S. O., et al. (2005). Orexin stimulates breathing via medullary and spinal pathways. J. Appl. Physiol. 98, 1387-1395. doi: 10.1152/japplphysiol.00914.2004 
Zhang, W., Fukuda, Y., and Kuwaki, T. (2005). Respiratory and cardiovascular actions of orexin-A in mice. Neurosci. Lett. 385, 131-136. doi: 10.1016/j.neulet.2005.05.032

Zicha, J., and Kunes, J. (1999). Ontogenetic aspects of hypertension development: analysis in the rat. Physiol. Rev. 79, 1227-1282.

Zimmerman, R. S., and Frohlich, E. D. (1990). Stress and hypertension. J. Hypertens. Suppl. 8, S103-S107.

Zoccal, D. B., Bonagamba, L. G., Paton, J. F., and Machado, B. H. (2009a). Sympathetic-mediated hypertension of awake juvenile rats submitted to chronic intermittent hypoxia is not linked to baroreflex dysfunction. Exp. Physiol. 94, 972-983. doi: 10.1113/expphysiol.2009. 048306

Zoccal, D. B., Paton, J. F., and Machado, B. H. (2009b). Do changes in the coupling between respiratory and sympathetic activities contribute to neurogenic hypertension? Clin. Exp. Pharmacol. Physiol. 36, 1188-1196. doi: 10.1111/j.14401681.2009.05202.x

Zoccal, D. B., and Machado, B. H. (2011). Coupling between respiratory and sympathetic activities as a novel mechanism underpinning neurogenic hypertension. Curr. Hypertens. Rep. 13, 229-236. doi: 10.1007/s11906-0110198-7

Zoccal, D. B., Simms, A. E., Bonagamba, L. G., Braga, V. A., Pickering, A. E., Paton, J. F., et al. (2008). Increased sympathetic outflow in juvenile rats submitted to chronic intermittent hypoxia correlates with enhanced expiratory activity. J. Physiol. 586, 3253-3265. doi: 10.1113/jphysiol.2008.154187

Zubcevic, J., Waki, H., Raizada, M. K., and Paton, J. F. (2011). Autonomic-immunevascular interaction: an emerging concept for neurogenic hypertension. Hypertension 57, 1026-1033. doi: 10.1161/HYPERTENSIONAHA.111.169748

Conflict of Interest Statement: The authors declare that the research was conducted in the absence of any commercial or financial relationships that could be construed as a potential conflict of interest.

Received: 08 November 2013; accepted: 25 January 2014; published online: 12 February 2014.

Citation: Li A and Nattie E (2014) Orexin, cardio-respiratory function, and hypertension. Front. Neurosci. 8:22. doi: 10.3389/fnins.2014.00022

This article was submitted to Neuropharmacology, a section of the journal Frontiers in Neuroscience.

Copyright (C) 2014 Li and Nattie. This is an open-access article distributed under the terms of the Creative Commons Attribution License (CC BY). The use, distribution or reproduction in other forums is permitted, provided the original author(s) or licensor are credited and that the original publication in this journal is cited, in accordance with accepted academic practice. No use, distribution or reproduction is permitted which does not comply with these terms. 